Article

\title{
Corrosion and Corrosion Fatigue Properties of Additively Manufactured Magnesium Alloy WE43 in Comparison to Titanium Alloy Ti-6Al-4V in Physiological Environment
}

\author{
Nils Wegner ${ }^{1, *}{ }^{\mathbb{C}}$, Daniel Kotzem ${ }^{1} \mathbb{D}$, Yvonne Wessarges ${ }^{2}$, Nicole Emminghaus ${ }^{2}$, \\ Christian Hoff ${ }^{2}$, Jochen Tenkamp ${ }^{1}$, Jörg Hermsdorf ${ }^{2}$, Ludger Overmeyer ${ }^{2}$ and Frank Walther ${ }^{1}$ (D) \\ 1 Department of Materials Test Engineering (WPT), TU Dortmund University, Baroper Str. 303, \\ D-44227 Dortmund, Germany \\ 2 Materials and Process Department, Laser Zentrum Hannover e.V. (LZH), Hollerithallee 8, \\ D-30419 Hannover, Germany \\ * Correspondence: nils.wegner@tu-dortmund.de; Tel.: +49-231-755-8727
}

Received: 15 August 2019; Accepted: 4 September 2019; Published: 7 September 2019

check for updates

\begin{abstract}
Laser powder bed fusion (L-PBF) of metals enables the manufacturing of highly complex geometries which opens new application fields in the medical sector, especially with regard to personalized implants. In comparison to conventional manufacturing techniques, L-PBF causes different microstructures, and thus, new challenges arise. The main objective of this work is to investigate the influence of different manufacturing parameters of the L-PBF process on the microstructure, process-induced porosity, as well as corrosion fatigue properties of the magnesium alloy WE43 and as a reference on the titanium alloy Ti-6Al-4V. In particular, the investigated magnesium alloy WE43 showed a strong process parameter dependence in terms of porosity (size and distribution), microstructure, corrosion rates, and corrosion fatigue properties. Cyclic tests with increased test duration caused an especially high decrease in fatigue strength for magnesium alloy WE43. It can be demonstrated that, due to high process-induced surface roughness, which supports locally intensified corrosion, multiple crack initiation sites are present, which is one of the main reasons for the drastic decrease in fatigue strength.
\end{abstract}

Keywords: additive manufacturing; laser powder bed fusion (L-PBF); magnesium alloy WE43; titanium alloy Ti-6Al-4V; biomaterials; corrosion; in vitro fatigue

\section{Introduction}

Due to higher life expectancy, people are facing new diseases, which can limit the quality of life. Therefore, a great deal of research activity has been carried out in the last century and the overall aim of these purposes has been superior medical solutions like biomedical implants and improving the perspectives of the patient [1]. Concerning the potential implant, only a few material classes can fulfill the challenging requirements. However, several metallic materials have been used since the early 1900s as scaffolds and for load-bearing implants [2]. Typical biomedical applications are wires, screws for fracture fixation plates, and joint prostheses for hips, knees, or shoulders [2]. Further on, metallic implants were used in cardiovascular surgery and dental medicine. The most commonly favored metals in the medical sector are stainless steel, titanium and its alloys, and cobalt-based as well as tantalum-based alloys [2].

In general, titanium alloys are preferred due to their high strength-to-weight ratio and corrosion resistance [3,4]. Further on, they show good biocompatibility due to the thin oxide layer which forms 
rapidly on the surface [5]. Titanium alloys show in vivo and in vitro superior corrosion resistance under static loading conditions due to the presence of the passive film on the surface [6]. Even if the passive film is damaged, repassivation takes place and limits metal dissolution. However, it has been demonstrated that cyclic loading negatively influences the metal dissolution as well as the repassivation kinetics [6]. As a consequence, the continuous breakdown of the passive film causes localized corrosion, which leads to decreased fatigue life and, further on, toxic metallic ions are released [7]. Another important drawback of titanium alloys as a biomaterial is the stiffness mismatch between the implant and the human bone, resulting in stress shielding which can cause bone resorption, resulting in loosening the implant. Thereby, different approaches, like the development of complex lattice structures or new materials, have been pursued in recent years. In this context, magnesium alloys are promising candidates with applications in the field of stents as well as reconstruction and fracture plates [8]. This is due to the natural occurrence of magnesium in the human body, the participation in many processes [9], and the similar mechanical properties to the human cortical bone preventing stress shielding [10]. Furthermore, the body can excrete it without harmful side effects, even at high concentrations [9]. A challenge with pure magnesium, however, is the excessively high and unpredictable corrosion rate under physiological environmental conditions with an associated release of hydrogen gas [11,12]. Also, the rapid degradation leads to a reduction of the cross-section and to the formation of corrosion scars, which drastically reduces the stability of the implant. With simultaneous mechanical loading, crack initiation occurs at these sites, which in turn are also a favored site for a corrosive attack so that these two effects reinforce each other [13-15].

The in vitro determination of corrosion rates is not a trivial issue. The corrosion behavior is influenced by the alloy composition and the microstructure [16]. Conventional methods such as potentiodynamic polarization (PDP) measurement provide inaccurate characteristic values by determining the corrosion current density and significantly underestimating the corrosion rate. The reason for this is the so-called negative difference effect (NDE), which, according to recent studies, can be explained by a cathodic activation of the samples under anodic polarization, so that surface films are formed which have a persistent cathodic effect. Consequently, the net anodic current density is reduced by a cathodic value [17-19]. Consequently, the classical immersion test with a detection of the hydrogen volume formed and a measurement of the weight reduction is the most accurate way to determine the corrosion rate.

There are few studies in the field of fatigue behavior of magnesium as a biomaterial. Many of them refer to the low cycle fatigue range [20-23], and only a few studies with superposition through body-like conditions could be found [23]. Above all, there is a lack of studies on the in vitro fatigue behavior of magnesium alloys containing rare earth elements (RE). One study series deals with the corrosion fatigue behavior of the magnesium alloy ZX10 with different extrusion temperatures in a simulated body fluid (SBF) [24], and a second publication deals with the corrosion fatigue behavior of different alloys under static and dynamic environmental conditions [25]. Despite the increasing interest in magnesium as a biomaterial, there is a lack of corrosion fatigue investigations under body-like conditions.

Additionally, structural circumstances inside the human body are challenging factors for potential implants, not only for the material but also for the manufacturing process. It is favored that implants are customized to the needs of the patient. Due to this, the implant shape has to be highly complex and conventional subtractive manufacturing methods are limited, thus, new manufacturing techniques have to be developed to take into account patients' requirements. Additive manufacturing (AM) has developed over the past years as a common technique to produce implants or medical devices with complex geometries [26,27]. Due to the high geometrical freedom, personalized implants with local adjusted material properties can be manufactured [28]. Concerning possible AM techniques, which can process titanium and magnesium alloys, especially powder bed fusion (PBF) techniques, using a high power heat source of either laser or electron beams for local melting of powder particles, are favored. Both techniques are based on the layer-by-layer manufacturing of components. In particular, the base 
plate is covered by a powder layer, which is subsequently melted by the heat source according to the corresponding CAD data. After this, the base plate is lowered and again covered with the powder [29]. This principle enables the manufacturing of highly complex geometries.

In comparison to electron powder bed fusion (E-PBF), laser powder bed fusion (L-PBF) achieves higher accuracy [28] and better as-built surface roughness [30] but has an increased process time compared to conventional methods [31]. Until now, high surface roughness and process-induced defects, such as porosity or near-surface notch-like defects, are limiting factors. Regarding in vivo applications, near-surface defects can facilitate corrosion processes which can end up in early failure of the implant and increased risk of toxicity [2]. Therefore, the material, especially the damage behavior of the used materials, has to be understood in detail. Much research was carried out in the origin of defects and they can mainly be reduced to process parameters during the manufacturing process [32]. For both types of implants, i.e. permanent and resorbable, representative material classes were manufactured by L-PBF. Despite the different material classes and the resulting areas of application, it should be shown to what extent the mechanical stability of magnesium is inferior to titanium. In the case of the permanent implant class, the Ti-6Al-4V alloy was selected, and for the resorbable implant class, the magnesium alloy WE43 was chosen. The main objective of this work was to highlight the influence of different process parameters on resulting microstructure, process-induced porosity, and corrosion fatigue strength for additively manufactured materials, especially for magnesium alloy WE43, to ensure a reliable application in future medical devices.

\section{Experimental Methods}

\subsection{Materials}

\subsubsection{Magnesium}

Investigations were conducted for two different biomedical materials. A resorbable material (magnesium alloy) was compared to a non-resorbable material (titanium alloy). Concerning magnesium, the powder material WE43 alloyed with yttrium and rare earth elements produced by LPW Technology Ltd (Cheshire, Great Britain) was used. The particle size range is between 20 to $63 \mu \mathrm{m}$. SEM (scanning electron microscopy, Thermo Fisher Scientific, Waltham, MA, USA) pictures, shown in Figure 1, reveal spherical particles with particle attachments and high amounts of fines. The biological compatibility of WE43 was confirmed several times, including cell survival rates of $96 \%$ (cell line L929), good in vivo integration with surrounding bone (rabbits, 2 months), and no adverse effects due to gas bubbles [33].

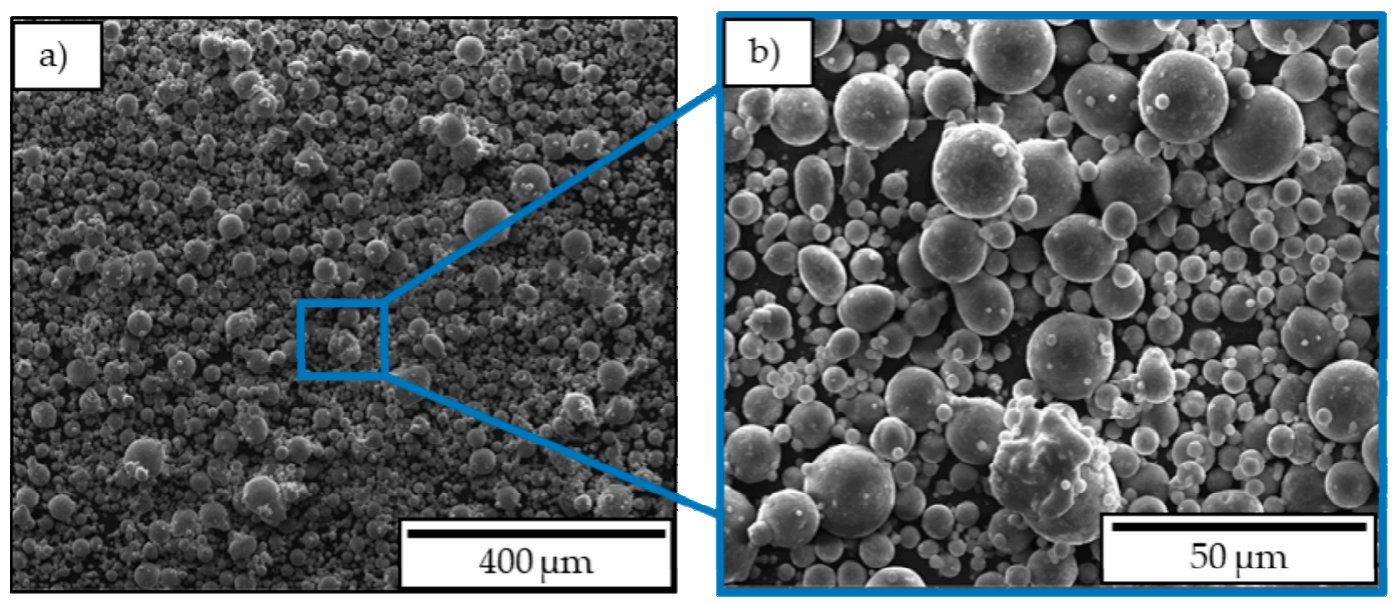

Figure 1. SEM images of a WE43 magnesium powder: $(\mathbf{a}) \times 500,(\mathbf{b}) \times 1000$ magnification.

The magnesium parts are manufactured using a modified SLM125HL system by SLM Solutions $\mathrm{GmbH}$ (Luebeck, Germany) with a $100 \mathrm{~W}$ continuous wave ytterbium fiber laser (see Figure 2). 
The modification of the machine was conducted to meet the advanced requirements of magnesium research and is therefore only useable for processing of magnesium powders to avoid contamination with other materials with regard to the manufacturing of medical implants. The laser has a wavelength of $1070 \mathrm{~nm}$, a focus diameter of $70 \mu \mathrm{m}$, and a beam quality of $\mathrm{M}^{2}<1.1$. The L-PBF build jobs are conducted in an argon gas atmosphere.

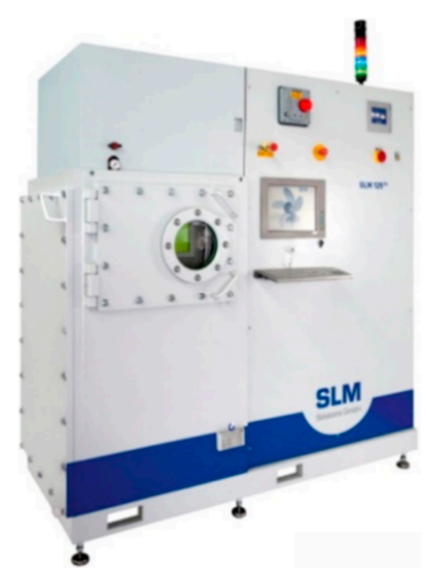

Figure 2. Modified SLM125HL system with overpressure chamber and build chamber reduction to $50 \times 50 \times 50 \mathrm{~mm}^{3}$.

Cylindrical specimens with different parameter combinations were manufactured for further investigation of the effect of different parameter settings and, therefore, different energy inputs during manufacturing. The parameters scanning speed, hatch distance, and layer size are varied. In addition, a double exposure was tested, which means that each layer of powder was coated and scanned twice, or in other words, the building platform was lowered only every second layer. The parameter settings are based on the results of preliminary investigations. The chosen parameter settings are given in Table 1. A laser power of $100 \mathrm{~W}$ was used.

Table 1. Parameter settings for magnesium specimens.

\begin{tabular}{cccc}
\hline Processing Parameter & Batch $\mathbf{A}_{\mathbf{M g}}$ & Batch $\mathbf{B}_{\mathbf{M g}}$ & Batch $\mathbf{C}_{\mathbf{M g}}$ \\
\hline Scanning speed in $\mathrm{mm} / \mathrm{s}$ & 1000 & 300 & 450 \\
\hline Hatch distance in $\mu \mathrm{m}$ & 15 & 110 & 100 \\
\hline Exposure & single & single & double \\
\hline Layer size in $\mu \mathrm{m}$ & 50 & 30 & 50 \\
\hline
\end{tabular}

\subsubsection{Titanium}

The material used for building the specimen is gas-atomized Ti-6Al-4V powder produced by Heraeus additive manufacturing $\mathrm{GmbH}$ with a particle size of 15 to $53 \mu \mathrm{m}$. A particle size analysis conducted by Heraeus additive manufacturing $\mathrm{GmbH}$ showed that $10 \%$ of the particles have a diameter smaller than $22.46 \mu \mathrm{m}$ and $90 \%$ have a diameter smaller than $53.68 \mu \mathrm{m}$. The chemical analysis revealed that the actual value of the aluminum content is $6.07 \mathrm{wt} \%$ and the vanadium content is $3.94 \mathrm{wt} \%$. SEM images, shown in Figure 3, were taken and analyzed to evaluate the particle geometry that appeared to be mostly spherical. 


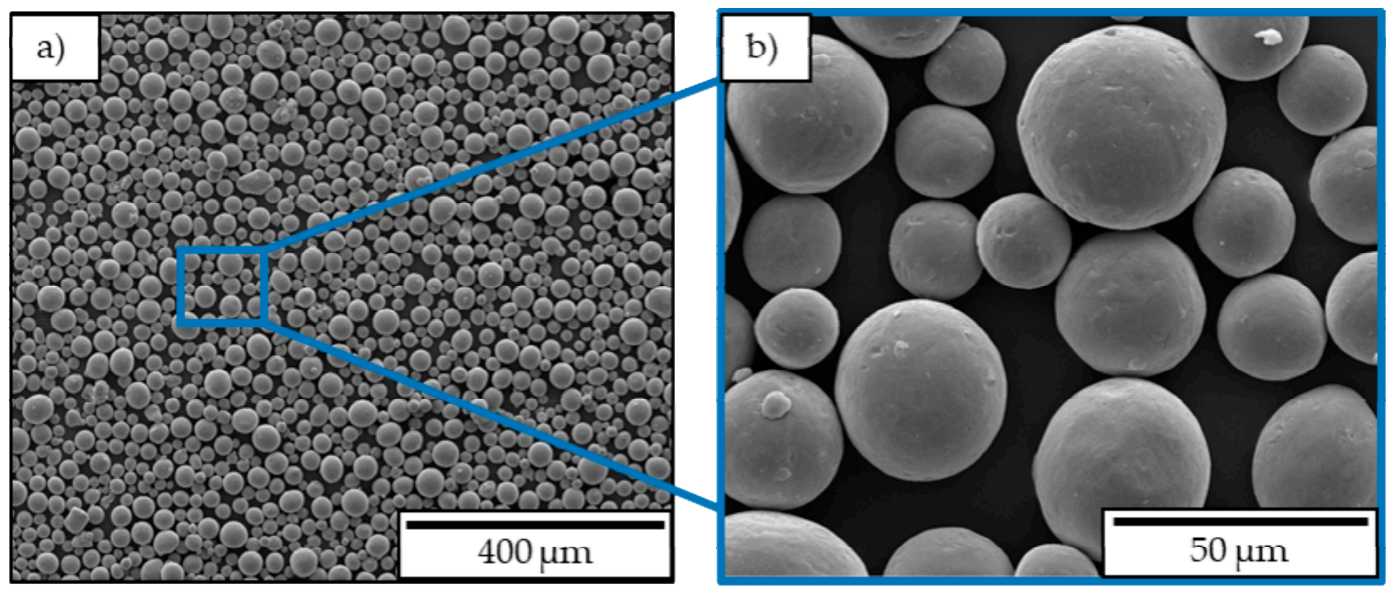

Figure 3. SEM images of Ti-6Al-4V powder: (a) $\times 250 ;(\mathbf{b}) \times 2000$ magnification.

The manufacturing parameters (laser power $\mathrm{P}_{\mathrm{L}}$, scanning speed $\mathrm{v}_{\mathrm{S}}$, hatch distance $\mathrm{d}_{\mathrm{H}}$ ) for building the test specimens are chosen according to the results of a preliminary parameter study. In this study, cubic specimen were built with different parameter settings using a design of experiments (DoE) approach. The evaluation of the results revealed three combinations of parameter settings that lead to high density parts and therefore promised favorable mechanical properties. The chosen parameter settings are shown in Table 2. Furthermore, a constant hatch distance of $60 \mu \mathrm{m}$ and a layer size of $30 \mu \mathrm{m}$ were implemented. Each layer was scanned only once.

Table 2. Parameter settings for titanium specimens.

\begin{tabular}{cccc}
\hline Processing Parameter & Batch $\mathbf{A}_{\mathbf{T i}}$ & Batch $\mathbf{B}_{\mathbf{T i}}$ & Batch $\mathbf{C}_{\mathbf{T i}}$ \\
\hline Laser power in $\mathrm{W}$ & 100 & 115 & 130 \\
\hline Scanning speed in $\mathrm{mm} / \mathrm{s}$ & 1000 & 1200 & 1400 \\
\hline
\end{tabular}

For each parameter, setting cylindrical specimens were built and the industrial machine Lasertec $12 \mathrm{SLM}$ (Realizer $\mathrm{GmbH}$, Borchen, Germany) was used. It was equipped with an ytterbium fiber laser (continuous wave, single mode) operating at a wavelength of $1070 \mathrm{~nm}$ with a maximum power of $400 \mathrm{~W}$, providing a laser beam with a beam quality factor of $\mathrm{M}^{2}=1.05$. The machine offers a minimum beam diameter of $35 \mu \mathrm{m}$ and a building volume of $125 \times 125 \times 200 \mathrm{~mm}^{3}$. To avoid oxidation, the process chamber is filled by the inert gas argon. This way, it is possible to reach a minimum residual oxygen content of 0.13 to $0.15 \mathrm{wt} \%$.

\subsubsection{Specimen Geometry}

With regard to cyclic testing under stress ratio $\mathrm{R}=10$, i.e. compression-compression, no standard in case of the specimen geometry is available in literature. Solely German standard DIN 50106 [34] can be used to determine boundary conditions for the fatigue experiments. According to the German standard, the specimen geometry was chosen based on the following ratio between height $\left(\mathrm{h}_{0}\right)$ and diameter $\left(\mathrm{d}_{0}\right)$ for magnesium and titanium:

$$
1 \leq \frac{\mathrm{h}_{0}}{\mathrm{~d}_{0}} \leq 2
$$

Therefore, the specimen diameter was set to $7 \mathrm{~mm}$ and height was set to $10.5 \mathrm{~mm}$, enabling a ratio of 1.5. The compliance of the above-mentioned ratio is necessary to prevent experimental problems like bending or buckling of the specimens. Further on, specimens were manufactured upright, which corresponds to load direction. Before testing, the front surfaces of the specimens were sanded and polished to be mirror-like and plane-parallel. 


\subsection{Computer Tomography}

Computer tomography (CT) provides a contactless and non-destructive insight into parts and structures. For both, magnesium and titanium specimens, porosity, and building defects are investigated. Therefore, the X-ray device nanotom 180 (GE Sensing and Inspection Technologies GmbH, Wunstorf, Germany (voxel size: $6 \mu \mathrm{m}$, voltage: $90 \mathrm{kV}$, current: $110 \mu \mathrm{A}$ )) is used to achieve the 3D data which is processed and visualized by the software VGStudio max (my VGL2.2, Volume Graphics GmbH, Heidelberg, Germany). To calculate the relative density, the provided 3D data is converted to a stack of 2D images representing slices through the part in building direction. These images are analyzed through a python script written at Laser Zentrum Hannover e.V. to calculate the ratio between dark (pores) and light pixels (dense material). The slicing distance is chosen with regard to the smallest distance between layers or hatches, respectively. Accordingly, for magnesium, a distance of $15 \mu \mathrm{m}$ (smallest hatch distance), and for titanium, a distance of $30 \mu \mathrm{m}$ (layer thickness) was chosen. An important option offered by the evaluation script is the possibility to exclude detected pores with a diameter under or over a specified value from the density calculation. This way, the influence of imaging artifacts like image noise on the calculation can be minimized. Additionally, the script measures the pore cross-section areas and gives out the mean and maximum pore sizes for every slicing image. The CT analysis was conducted for three specimens of each batch. For each specimen, the mean value for the relative density was calculated. To verify the CT results, they were compared to density values achieved through image analysis of polished specimen sections.

\subsection{Microstructure}

Parts manufactured by L-PBF are known to show different microstructures compared to parts achieved through casting or forging. Mechanical, as well as corrosion, properties depend strongly on the phases and grain morphologies. Hence, it is important to investigate the achieved microstructure in the built specimens. The manufactured samples follow a metallographic preparation route consisting of cold embedding in an epoxy resin (Technovit Epox, Kulzer GmbH, Hanau, Germany), grinding, polishing (Tegramin, Struers ApS, Ballerup, Danemark) and etching in Nital 2\% and Kroll's reagent for magnesium and titanium, respectively. For microstructural analysis, light microscopy was employed (Aristomet, Leica Microsystems GmbH, Wetzlar, Germany), in which the samples were analyzed in their center and near the surface, in cross-sections parallel to the building direction. For fractographic analysis, the SEM Mira 3 XMU (Tescan, Brno, Czech Republic) was used.

\subsection{Corrosion Tests}

In order to characterize the corrosion behavior and to determine the corrosion rates, the immersion test was chosen in addition to the PDP. PDP only provides qualitatively comparable results, the reason for choosing the NDE having been described in the introduction. The immersion tests, on the other hand, provide quantitatively comparable results. For comparability of the tests, a simulated body fluid (SBF) according to Kokubo et al. [35] at $37^{\circ} \mathrm{C}$ is used in both the PDP and the immersion tests (Table 3). The $\mathrm{pH}$ value is adjusted to 7.5 via 0.1 molar $\mathrm{HCl}$. In order to obtain a direct correlation between PDP and immersion tests, the same samples were used for both test methods. The cylindrical specimens are cold embedded upright in an epoxy resin and sanded with grinding discs with grits of 800 to 2500 and polished to 6,3 , and $1 \mu \mathrm{m}$ with a water-free diamond suspension. Before the immersion tests, the corrosion layer from the PDP is removed in the same way. For a first estimation of the corrosion behavior, polished surfaces are investigated instead of 'as-built' surfaces to eliminate the influence of surface roughness. A backside drilling through the embedding material enables the contacting for the electrochemical measurements. An overview of the sample preparations before the respective investigations is given in Figure 4. 


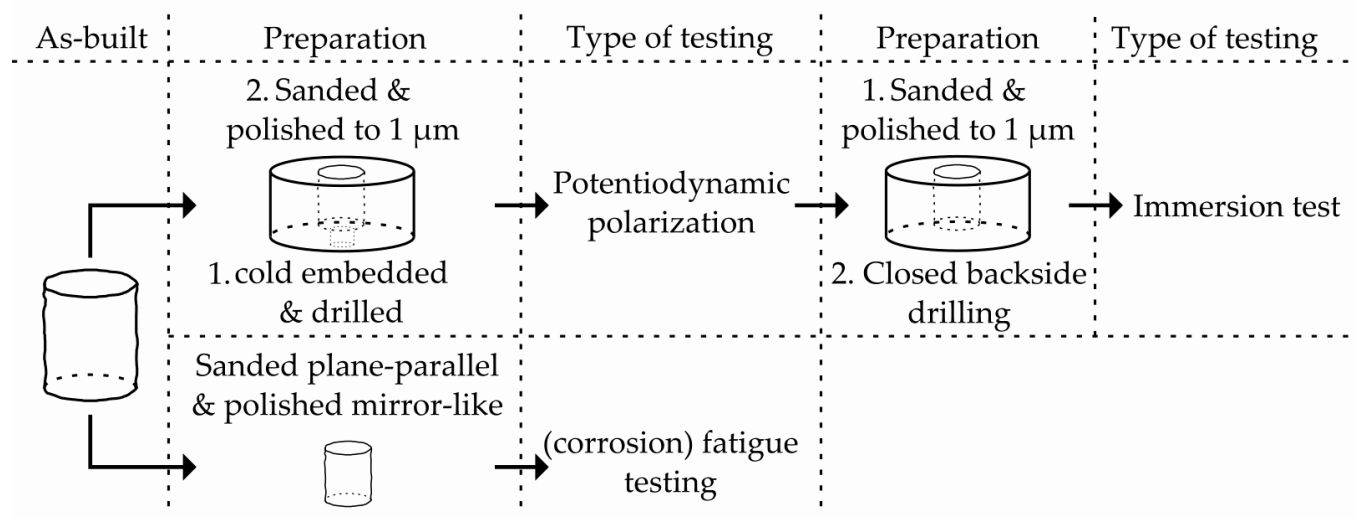

Figure 4. Overview of the sample preparation.

Table 3. Ion concentration of the used simulated body fluid according to [35].

\begin{tabular}{cccccccc}
\hline \multicolumn{8}{c}{ Ion Concentration in mmol/L } \\
\hline $\begin{array}{c}\text { Simulated Body } \\
\text { Fluid (SBF) }\end{array}$ & $\mathbf{N a}^{+}$ & $\mathbf{K}^{+}$ & $\mathbf{C a}^{2+}$ & $\mathbf{M g}^{2+}$ & $\left(\mathrm{HCO}_{3}\right)^{-}$ & $\mathbf{C l}^{-}$ & $\left(\mathbf{H P O}_{4}\right)^{2-}$ \\
\cline { 2 - 8 } & 142.0 & 5.0 & 2.5 & 1.5 & 4.2 & 147.8 & 1.0 \\
\hline
\end{tabular}

\subsubsection{Potentiodynamic Polarization}

A standard three-electrode system was used for this test method, and the test setup is shown in Figure 5a. The electrolyte was tempered via a hot plate with its control circuit and circulated via two pump circuits of a peristaltic pump so that a temperature of $37^{\circ} \mathrm{C}$ is reached inside the corrosion cell. The inlet and outlet of the electrolyte were aligned in such a way that any influence on the electrochemical measurement was kept to a minimum. The embedded sample was pressed via an O-ring against an opening in the corrosion cell so that the polished surface was in contact with the electrolyte. For the three-electrode system, an $\mathrm{Ag} / \mathrm{AgCl}$ electrode was used as a reference electrode and a graphite electrode as a counter electrode. The experimental setup, including the corrosion cell, was located in a Faraday cage, whereas the electrical devices (hot plate, peristaltic pump) were located outside the cage. Before carrying out the measurements, the open circuit potential (OCP) was measured for $30 \mathrm{~min}$. Afterward, the sample was polarized with a potential feed of $0.8 \mathrm{mV} \mathrm{s}^{-1}$ within a potential range of $\pm 300 \mathrm{mV}$. The Gamry potentiostat PCI4300 (Gamry Instruments Inc, Warminster, PA, USA) was used, as well as the corresponding Gamry Echem Analyst software, to evaluate the corrosion current density $i_{\text {corr }}$ based on the Butler-Volmer equation.

\subsubsection{Immersion Tests}

As described before, the same samples of the PDP were used, only the drilling on the back was closed. A double-walled corrosion cell was used, whereby distilled water is conveyed through the outer jacket by a thermostat so that a temperature of $37^{\circ} \mathrm{C}$ is reached in the inner jacket. The sample was placed below a burette (total volume $10 \mathrm{~mL}$, calibration marks at $0.02 \mathrm{~mL}$ ) so that the hydrogen produced was collected by the burette funnel and the volume can be determined from the level inside the burette. Due to the high ratio of electrolyte volume to sample surface and the short test times, no saturation effects are expected. The tests are carried out until a constant corrosion rate is reached. For evaluation, the specific hydrogen volume is plotted over the immersion time. The corrosion rate is determined by the slope of the linear section of a compensation curve.

\subsection{Corrosion Fatigue Tests}

Based on the results of the corrosion tests on magnesium, two batches (batch $A_{M g}$ and $B_{M g}$ ) were chosen for the cyclic tests, which suggests the greatest differences in fatigue behavior. For titanium, one batch (batch $\mathrm{R}_{\mathrm{Ti}}$ ) was selected for the corrosion fatigue tests, based on results from CT analysis. 
Constant amplitude tests (CAT) were carried out in SBF at $37^{\circ} \mathrm{C}$ to simulate in vivo conditions and as a reference in air at room temperature (RT). The same electrolyte was used as was used in the corrosion tests. The investigations were carried out on a servo-hydraulic testing machine Schenck PC 63M with Instron 8800 controller (Instron, Norwood, MA, USA $\left(\mathrm{F}_{\max }= \pm 45 \mathrm{kN}\right)$ ) with adapted compression dies (Inconel 602), as well as tungsten carbide plates mounted on the end faces. An in vitro corrosion cell was developed to enable a medial superposition by the SBF (Figure 5b). In order to reach a constant temperature of $37^{\circ} \mathrm{C}$ and to prevent saturation effects inside the cell, the test setup was instrumented with a thermostat and a peristaltic pump. The minimum volume flow of the peristaltic pump and the internal diameter of the tubes used resulted in a fluid velocity of $0.003 \mathrm{~m} / \mathrm{s}$ via continuity law. Thus, the flow velocity used is far below the mean aortic velocity of a human $(1.12-1.32 \mathrm{~m} / \mathrm{s})$ [36], so that the influence of the velocity on the corrosion behavior is negligible. In order to prevent the specimens from galvanic corrosion, the compression dies, together with the tungsten, carbide plates were coated with a polyurethane lacquer.
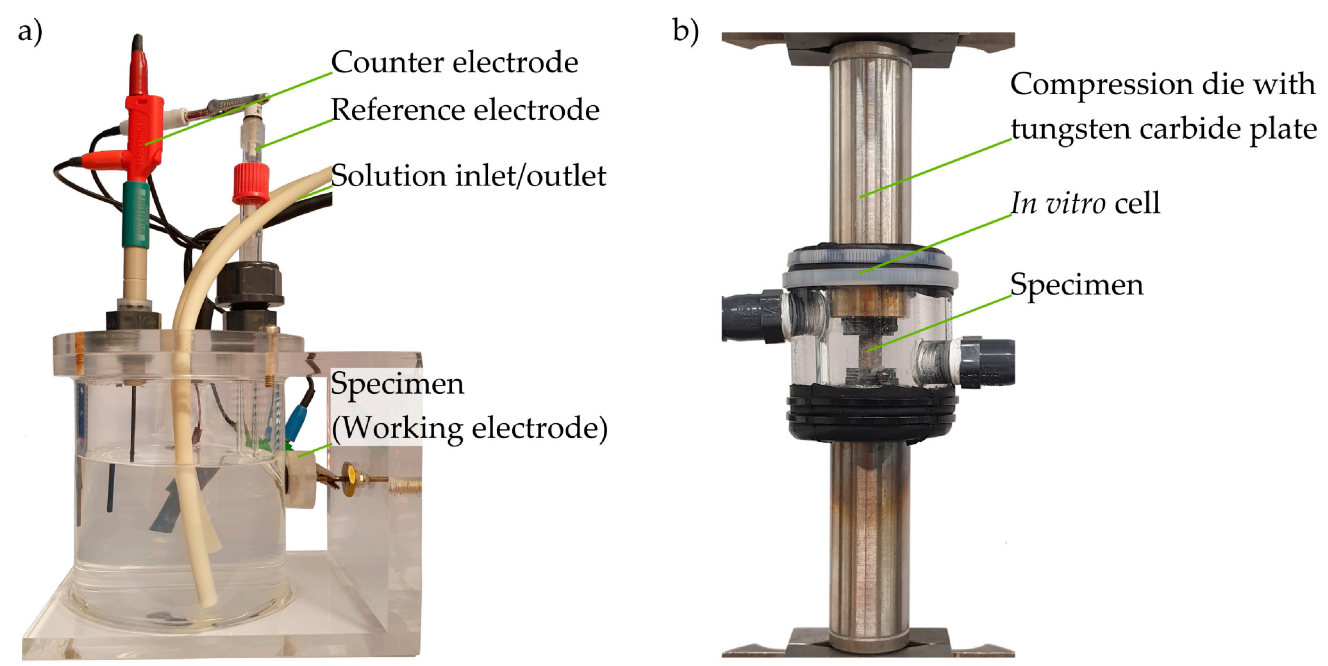

Figure 5. Experimental setup for (a) potentiodynamic polarization measurements; (b) corrosion fatigue tests.

CAT was performed at a stress ratio of $\mathrm{R}=10$ (compression-compression), a sinusoidal stress-time function, and a constant test frequency of $\mathrm{f}_{\mathrm{Mg}}=10 \mathrm{~Hz}$ and $\mathrm{f}_{\mathrm{Ti}}=5 \mathrm{~Hz}$. Based on previous investigations, a lower frequency was selected for titanium to prevent a significant increase in temperature. The stress ratio is considered as the first estimation for an implant that is mainly loaded by compression. For further investigations, the experimental setup and the specimen geometry can be adapted for other applications and stress ratios. The tests were carried out until the final fracture of the specimen and a run out was defined with a maximum number of cycles of $\mathrm{N}_{\text {limit }}=2 \times 10^{6}$. Since the tests on the titanium specimens are only used as a reference to the biodegradable magnesium, the maximum number of cycles was adapted to magnesium, based on the results of the corrosion fatigue tests.

\section{Results}

\subsection{Computer Tomography}

All specimens showed mostly dense material on the CT images and a high relative density of over $99.8 \%$ in the subsequent analysis. Due to the high image noise, a suitable greyscale threshold had to be found and a threshold value of 65 (black $=0$, white $=255$ ) offered the best differentiation between pores and dense material. In addition, detected pores with a diameter of under $15 \mu \mathrm{m}$ were identified to be imaging artifacts caused by image noise and therefore were excluded from the further analysis. Figure 6 shows an example of a CT image after the analysis. Pores are marked red and the 
contour is marked in light green. Regarding the individual pores, there generally are two types of defect geometries. On one hand, there are large and irregular pores, and on the other hand, there are small, spherical pores that also outnumber the irregular ones.

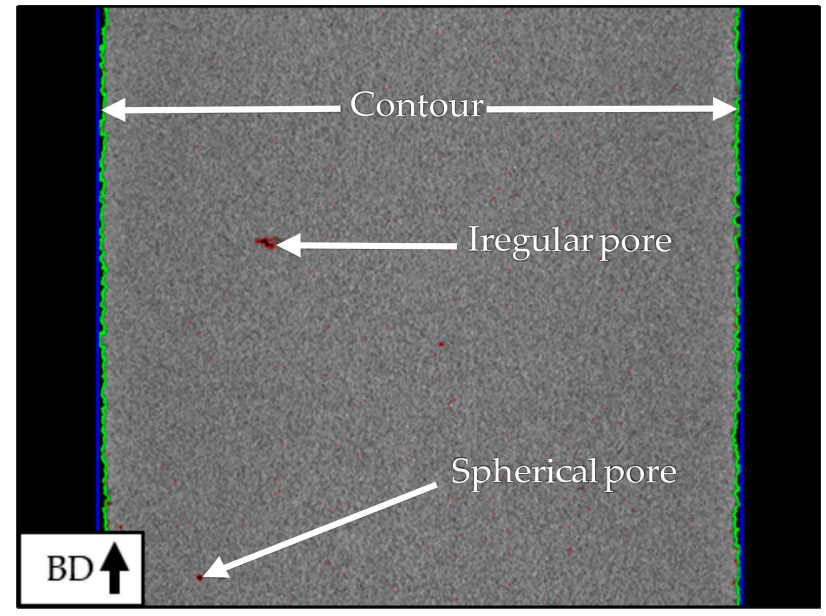

Figure 6. Computer tomography image of cylindrical titanium specimen.

\subsubsection{Magnesium}

Based on the computer tomography data, the mean relative density for three specimens for each batch was calculated (see Figure 7).
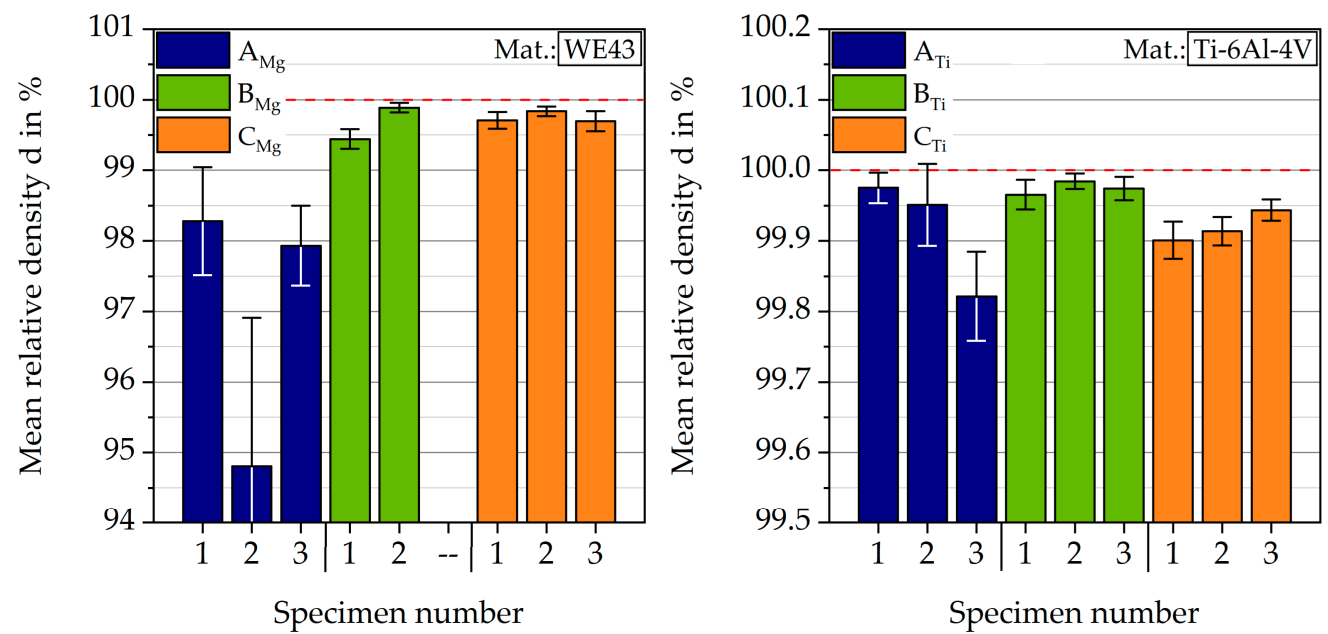

Figure 7. Mean relative densities of magnesium and titanium specimens.

The CT dataset of one specimen from batch $\mathrm{B}_{\mathrm{Mg}}$ was damaged, which led to only two calculated densities for batch $B_{\mathrm{Mg}}$. The second specimen within batch $B_{\mathrm{Mg}}$ with a smaller layer size of $30 \mu \mathrm{m}$ reveals the highest mean relative density of $99.89 \%$. This specimen also shows the smallest standard deviation of $0.07 \%$ relative density. A high mean density of $99.84 \pm 0.07 \%$ was also detected for the second specimen of batch $\mathrm{C}_{\mathrm{Mg}}$ with a double exposure build strategy. The second specimen of batch $\mathrm{A}_{\mathrm{Mg}}$ leads to the lowest calculated mean relative density of $94.80 \%$. For this specimen, the highest standard deviation of $2.11 \%$ relative density was found. The investigated specimens show an increasing standard deviation with decreasing mean relative density. To verify the results from $\mathrm{CT}$, the relative density is also measured in cross-sections after metallographic preparation by the use of image analysis (the mean value is calculated of the three specimens for three cross-sections each). For batch $\mathrm{B}_{\mathrm{Mg}}$ the similar relative densities with $99.89 \pm 0.06 \%$ was measured. The relative density of 
batch $\mathrm{C}_{\mathrm{Mg}}$ is with $99.84 \pm 0.07 \%$, slightly higher than the value received from the $\mathrm{CT}$ data. The relative density measured in the cross-sections of samples from batch $\mathrm{A}_{\mathrm{Mg}}$ reveals a higher relative density of $97.13 \pm 0.76 \%$.

The calculated mean and maximum pore sizes are given in Figure 8. In general, specimens of batch $B_{M g}$ show the smallest mean pore area, between 350 and $450 \mu \mathrm{m}^{2}$. For specimens from batch $\mathrm{C}_{\mathrm{Mg}}$, mean pore areas between 650 and $1100 \mu \mathrm{m}^{2}$ were detected. For batch $\mathrm{A}_{\mathrm{Mg}}$, a high spreading was found, with mean pore areas between 700 and $2200 \mu \mathrm{m}^{2}$. The specimens of batch $B_{\mathrm{Mg}}$ show the smallest pore areas with about 15,000 and 25,200 $\mu \mathrm{m}^{2}$. Specimens from batch $\mathrm{A}_{\mathrm{Mg}}$ and $\mathrm{C}_{\mathrm{Mg}}$ both lead to bigger pores, with calculated maximum pore areas between 76,000 and $131,900 \mu^{2}$.
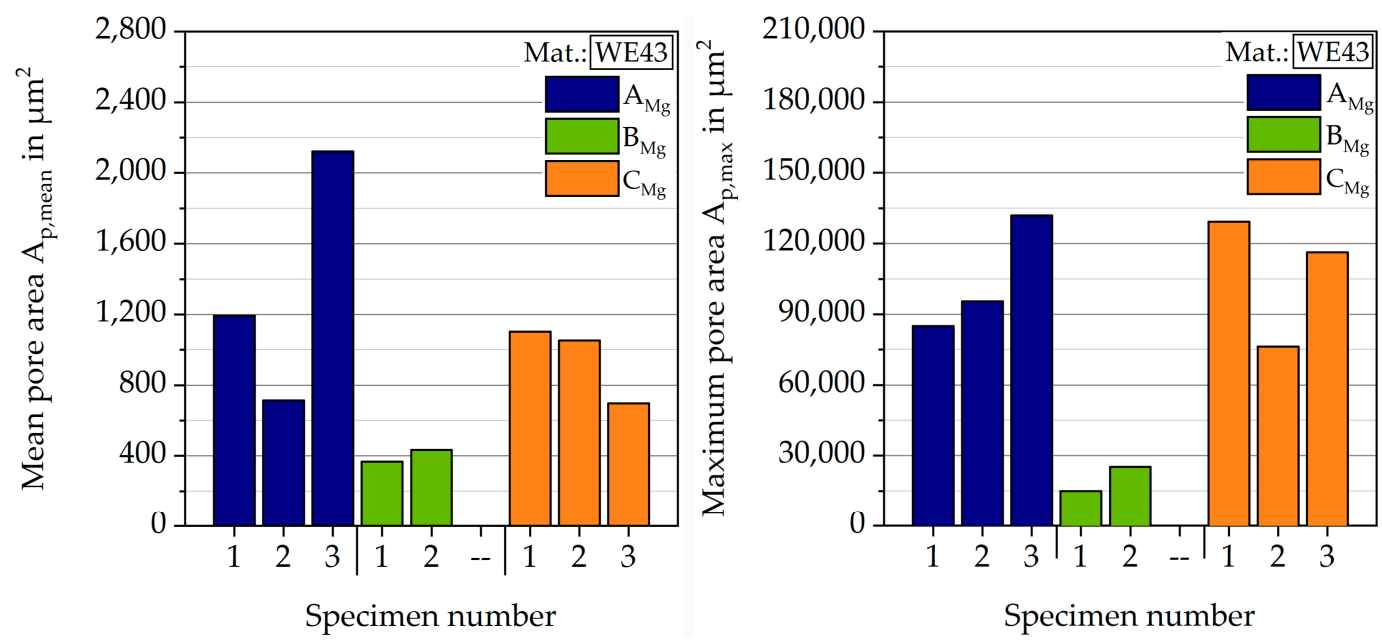

Figure 8. Mean and maximum pore area of magnesium specimens.

\subsubsection{Titanium}

For all tested specimens, the mean relative density of all slices, as well as the standard deviation, were calculated, and are displayed in Figure 7.

The highest mean value of $99.98 \%$ relative density was detected for batch $\mathrm{B}_{\mathrm{Ti}}$. Additionally, this specimen also showed the smallest standard deviation of $0.01 \%$ relative density. A minimum value for the relative density of $99.82 \%$ and the maximum standard deviation of $0.06 \%$ were calculated for the third specimen of batch $\mathrm{A}_{\mathrm{Ti}}$. Generally, an increasing standard deviation was observed for a decreasing relative density. Of all parameter settings, batch $\mathrm{A}_{\mathrm{Ti}}$ led to the specimens with the lowest relative density and with the highest standard deviation of the relative density. As for magnesium, the CT results were compared to the relative density evaluated through microscope image analysis of polished specimen sections. These values were slightly lower with mean values of $99.06 \%, 99.21 \%$, and $99.69 \%$ for the batches $\mathrm{A}_{\mathrm{Ti}}, \mathrm{B}_{\mathrm{Ti}}$, and $\mathrm{C}_{\mathrm{Ti}}$, respectively. Nevertheless, it could be shown that high densities of over $99 \%$ can be achieved.

In addition to the relative densities, the mean and the maximum pore size were calculated for each sample, displayed in Figure 9, respectively. Except for one specimen of batch $\mathrm{A}_{\mathrm{Ti}}$, all specimens had a mean pore area between 250 and $400 \mu \mathrm{m}^{2}$ and the biggest pore had an area of under 10,000 $\mu \mathrm{m}^{2}$. The one exceptional high value could, therefore, be regarded as an outlier.

Since Ti-6Al-4V is used here as a reference for the magnesium alloy and all three batches show similar microstructure and process-induced porosity, only specimens from batch $\mathrm{B}_{\mathrm{Ti}}$, which have, by comparison, the highest relative density, were used for mechanical testing. They will be subsequently named as batch $\mathrm{R}_{\mathrm{Ti}}$. 


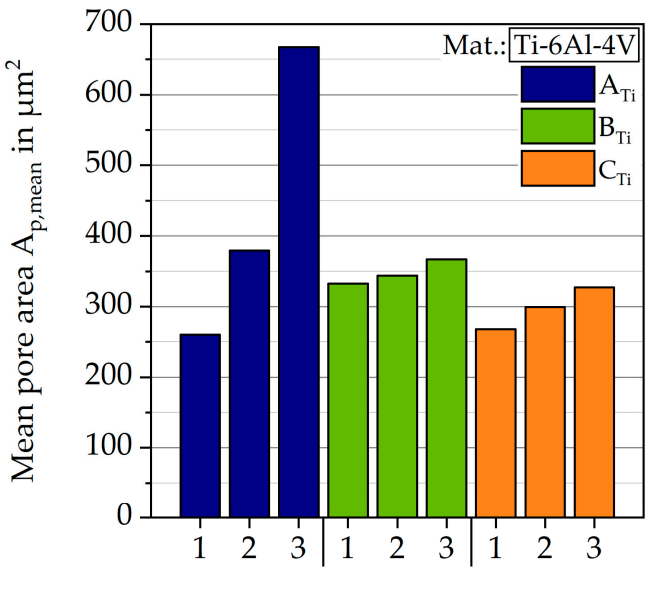

Specimen number

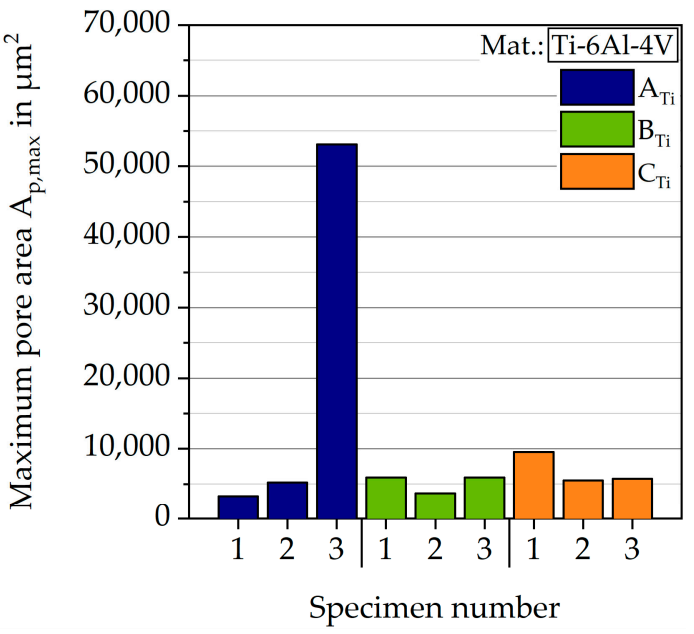

Figure 9. Mean and maximum pore area of titanium specimens.

\subsection{Microstructure}

\subsubsection{Magnesium}

In lower magnifications of $200 \times$ (Figure 10), it is possible to verify that not only the general morphology of the solidified melting pools varies between the different batches, but also that all samples present a number of heterogeneities along its microstructure. While the cross-sections associated to batch $\mathrm{A}_{\mathrm{Mg}}$ ( $\mathrm{a}$ and $\mathrm{d}$ ) show many small, single solidified melt pools, batch $\mathrm{B}_{\mathrm{Mg}}$ ( $\mathrm{b}$ and e) and $\mathrm{C}_{\mathrm{Mg}}$ (c and f) present bigger and deeper melt pools, a consequence of lower scan speeds and, therefore, higher energy inputs. Batch $\mathrm{C}_{\mathrm{Mg}}$, in turn, presents a melt pool superimposition without an overlapping zone, which increases the general energy input and is correlated to the double laser beam exposure. The aforementioned melt pool depths have been measured to be approximately 1, 5-6, and 3-4 times the layer size for batches $A_{M g}, B_{M g}$, and $C_{M g}$, respectively. The center of the cross-section of the samples belonging to batch $A_{M g}$ shows small single melt pools compared to $B_{M g}$ and $C_{M g}$. In contrast, the surface of the samples belonging to batch $A_{M g}$ shows greater melt pools. This is correlated with the decreased thermal conductivity of the surrounding powder bed, resulting in an accumulation of heat, whereas the higher thermal conductivity in the bulk material leads to smaller melt pools.
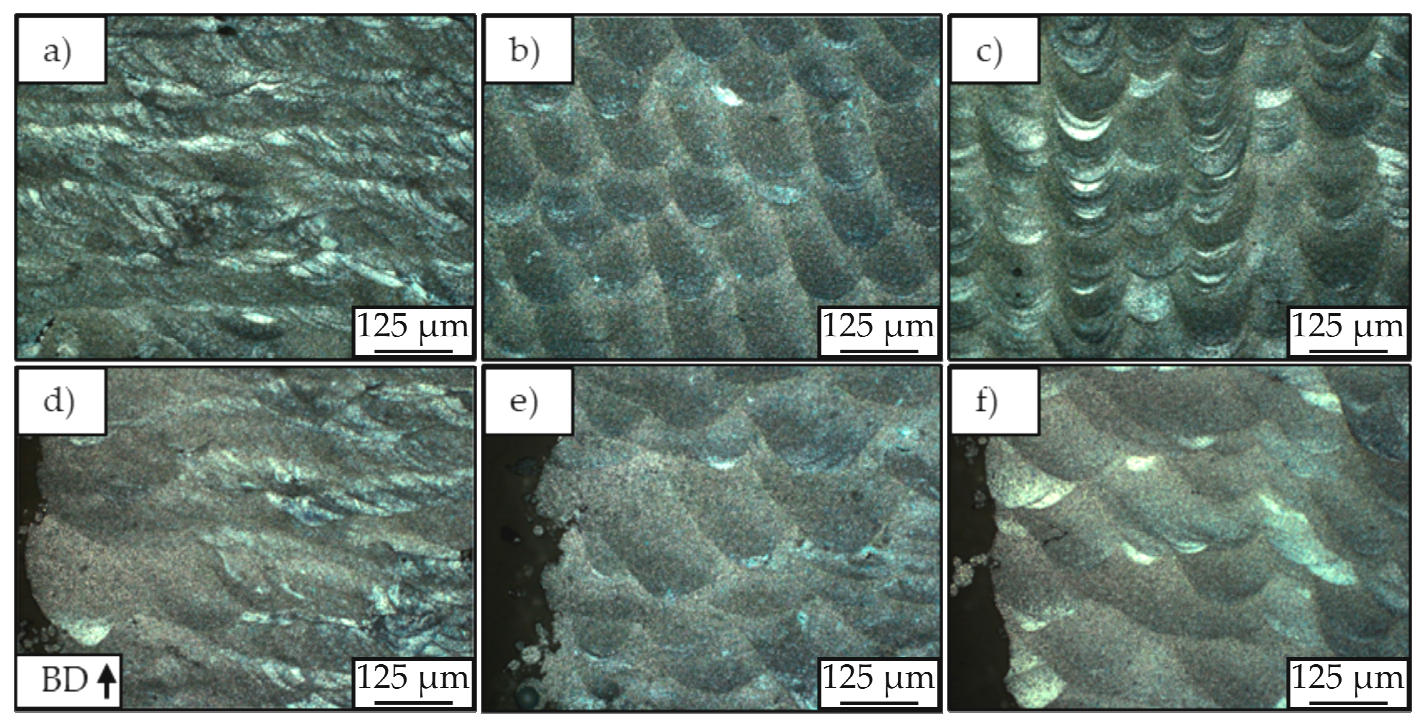

Figure 10. Light microscopy pictures of center $(\mathbf{a}-\mathbf{c})$ and surface $(\mathbf{d}-\mathbf{f})$ of samples in batch $\mathrm{A}_{\mathrm{Mg}}(\mathbf{a}, \mathbf{d})$, $\mathrm{B}_{\mathrm{Mg}}(\mathbf{b}, \mathbf{e})$ and $\mathrm{C}_{\mathrm{Mg}}(\mathbf{c}, \mathbf{f})$. Etchant: Nital $2 \%$. 
Higher magnifications of $1000 \times$ permit the estimation of the grain sizes associated to each batch. All conditions present very fine grains with diameters of a few micrometers, whose size seems to show little to no increase in the partially molten regions of the heat affected zone (Figure 11). Although the grain boundaries are weakly etched, a network of dark phases can be identified in such regions, which permits the identification of grain sizes.

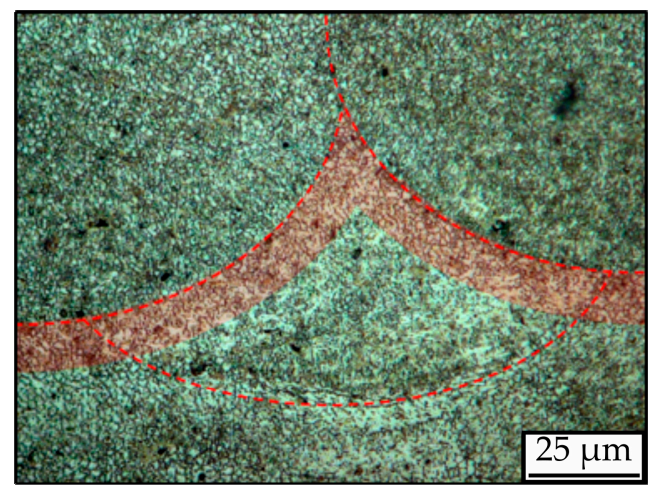

Figure 11. Heat affected zone of superimposition region of two neighboring melt pools in a sample of batch $\mathrm{B}_{\mathrm{Mg}}$. Etchant: Nital 2\%.

Regions poor in such intergranular phase network are also identified, especially in samples of batch $A_{M g}$ (Figure 12). Such regions appear brighter in the light microscopy pictures, given their higher reflectivity when compared to densely precipitated regions. Precipitation is, however, still present in these areas, mostly in the interfacial region between the melt pool and the heat affected zone.

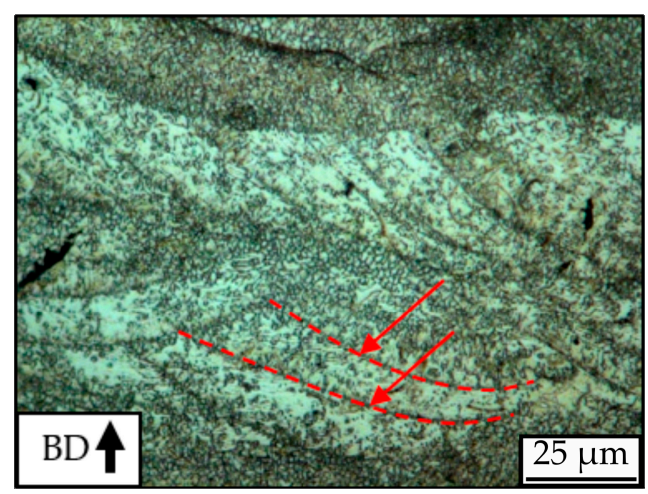

Figure 12. Region poor in intergranular intermetallic network, sample of batch $\mathrm{A}_{\mathrm{Mg}}$. Etchant: Nital $2 \%$; red lines show interfacial precipitation.

\subsubsection{Titanium}

Other than for magnesium, the microstructural analysis of the titanium specimens did not reveal visible solidified melt pools or clear borders between the single layers. All batches led to a similar microstructure, as can be seen in Figure 13. 


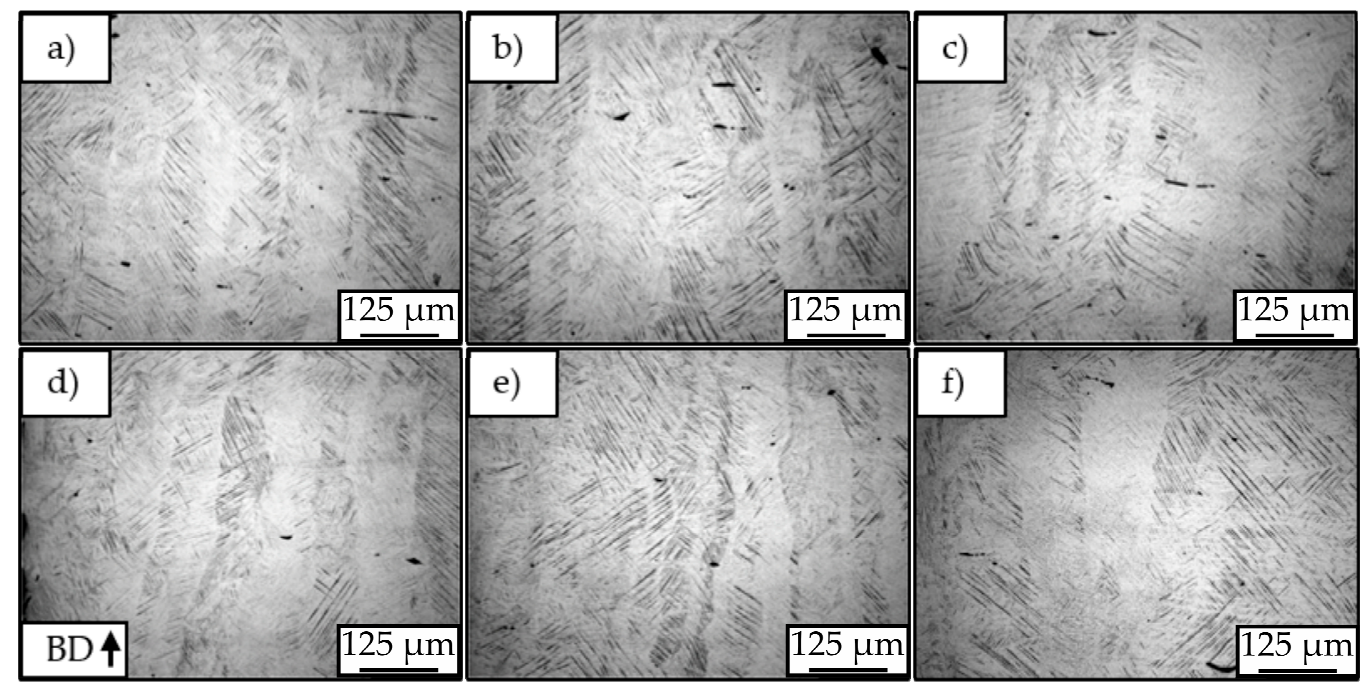

Figure 13. Light microscopy pictures of center $(\mathbf{a}-\mathbf{c})$ and left side surface $(\mathbf{d}-\mathbf{f})$ of batch $\mathrm{A}_{\mathrm{Ti}}(\mathbf{a}, \mathbf{d}), \mathrm{B}_{\mathrm{Ti}}$ $(\mathbf{b}, \mathbf{e})$ and $\mathrm{C}_{\mathrm{Ti}}(\mathbf{c}, \mathbf{f})$. Etchant: Kroll's reagent.

For all specimens, the typical microstructure of L-PBF processed Ti-6Al-4V was observed that was also described in different literature $[30,37,38]$. As the microscopy pictures show, the microstructure exhibits elongated prior- $\beta$ grains filled with fine $\alpha^{\prime}$-martensite laths of different lengths and widths. These martensite laths are oriented around $45^{\circ}$ to the building direction. The measurement of the microscope images revealed a width of the prior- $\beta$ grains up to around $300 \mu \mathrm{m}$. Near the surface (Figure $13 \mathrm{~d}-\mathrm{f}$ ), the grains are slightly smaller and less oriented than in the center of the samples $(\mathrm{a}, \mathrm{b}, \mathrm{c})$. The microscopy pictures with smaller magnifications (Figure 14) reveal a slight refinement of the microstructure with increasing laser power and scanning speed, due to the simultaneous increase of these parameters a decrease in laser energy input. Visible signs of the refined microstructure are a decrease in width of the prior- $\beta$ grains and therefore a decrease in the length of the $\alpha^{\prime}$-martensite laths.

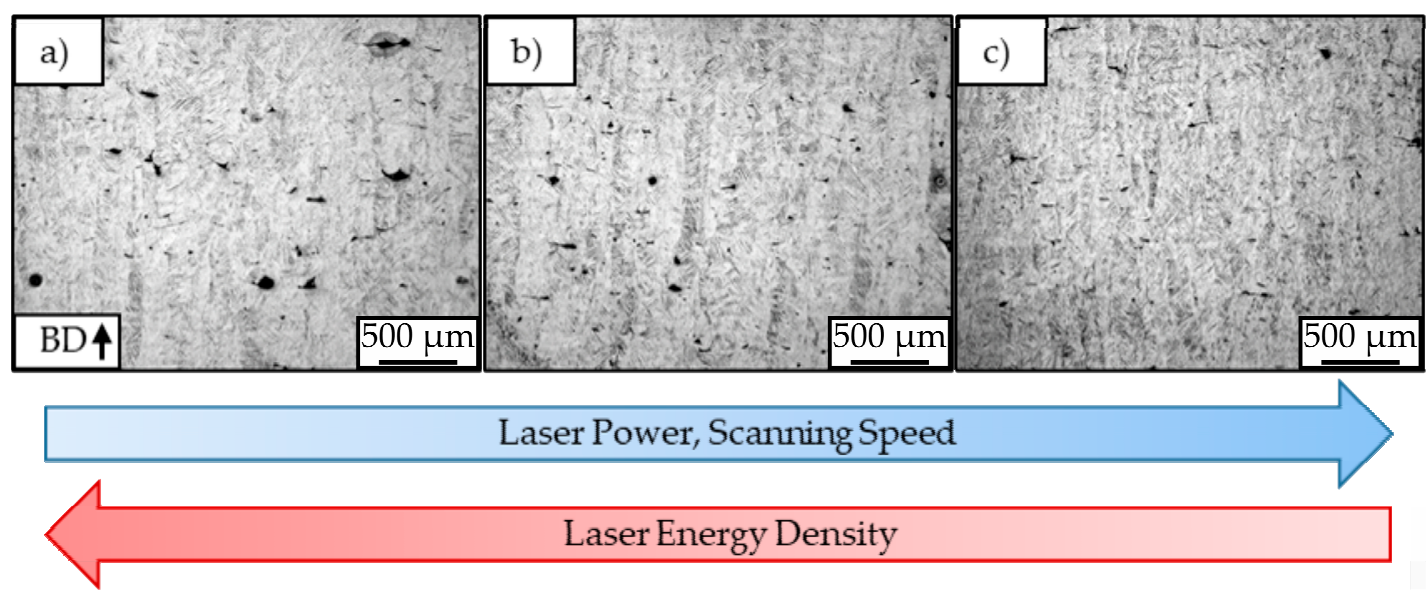

Figure 14. Microstructure for different batches $\mathrm{A}_{\mathrm{Ti}}(\mathbf{a}), \mathrm{B}_{\mathrm{Ti}}(\mathbf{b})$, and $\mathrm{C}_{\mathrm{Ti}}(\mathbf{c})$.

Figure 15 offers a closer look at the grain and martensite morphology. The grain boundaries are marked red exemplarily for one grain for better visibility (a). As described in [38,39], different types of $\alpha^{\prime}$-martensite can be recognized through their different lath sizes and orientations: Primary, secondary, tertiary, and quadric martensite (b). 


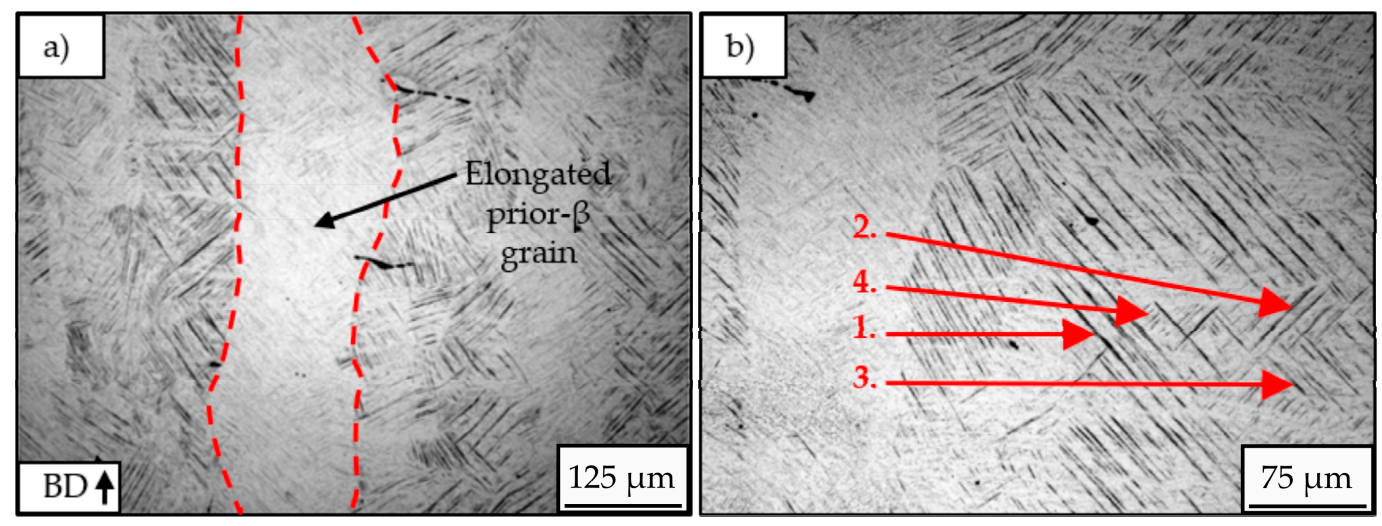

Figure 15. L-PBF typical acicular $\alpha^{\prime}$-martensite structure: (a) elongated prior- $\beta$ grains, (b) different martensites (1. primary, 2. secondary, 3. tertiary, 4. quartic).

\subsection{Corrosion Tests}

\subsubsection{Potentiodynamic Polarization}

The execution of PDP measurements is valid for a first estimation of the corrosion resistance and corrosion rate $\dot{\mathrm{m}}_{\mathrm{corr}}$ by determining the corrosion potential $\mathrm{E}_{\mathrm{corr}}$ and the corrosion current density $\mathrm{i}_{\text {corr }}$. Figure 16 shows the corresponding results as a Tafel plot so that the current density li| is plotted semi-logarithmically over the potential $\mathrm{E}$ relative to an $\mathrm{Ag} / \mathrm{AgCl}$ electrode. In addition, the respective characteristic values are listed in Table 4 . The different batches show a qualitatively similar course and differ barely in their corrosion potentials $\mathrm{E}_{\text {corr }}\left(-1.50 \mathrm{~V}\right.$ for batch $\mathrm{A}_{\mathrm{Mg}},-1.56 \mathrm{~V}$ for batch $\left.\mathrm{C}_{\mathrm{Mg}}\right)$. The anodic Tafel lines have a similar gradient and no passivation area is recognizable. The corrosion rates are calculated using $i_{\text {corr }}$ based on Faraday's law, whereby $i_{\text {corr }}$ is determined using Gamry Echem Analyst software based on the Butler-Volmer equation. In contrast to the corrosion potentials, batch $\mathrm{A}_{\mathrm{Mg}}$ had the highest and batch $\mathrm{B}_{\mathrm{Mg}}$ had the lowest $\mathrm{i}_{\text {corr }}$, consequently $\dot{\mathrm{m}}_{\text {corr }}$ is calculated to $1.5 \cdot 10^{3} \mathrm{mg} /\left(\mathrm{cm}^{2}\right.$ a) for batch $A_{\mathrm{Mg}}$ and $0.6 \cdot 10^{3} \mathrm{mg} /\left(\mathrm{cm}^{2}\right.$ a) for batch $B_{\mathrm{Mg}}$.

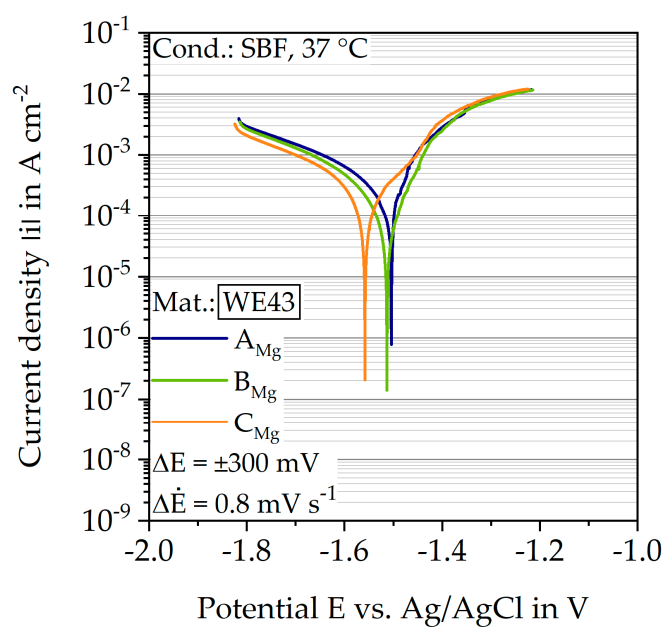

Figure 16. Results of the potentiodynamic polarizations measurements of the three batches in SBF, shown as Tafel plot.

\subsubsection{Immersion Tests}

Figure 17 shows the results of the immersion tests of the three batches in SBF at $37^{\circ} \mathrm{C}$. The specific hydrogen formation $\mathrm{V}_{\mathrm{H}_{2} \text {,spec }}$ is plotted as a function of the immersion time $t$. For all three batches, a qualitatively similar, progressive course is recognizable. $\mathrm{V}_{\mathrm{H}_{2} \text {,spec }}$ increases linearly after a start interval 
of 3 to $4 \mathrm{~h}$. Accordingly, a constant hydrogen formation rate occurs after this time, and this slope is used to calculate through a linear approximation $\dot{m}_{\text {corr }}$ (Table 4). Batch $\mathrm{A}_{\mathrm{Mg}}$ reached the highest value with $7.2 \cdot 10^{3} \mathrm{mg} /\left(\mathrm{cm}^{2} \mathrm{a}\right)$ and batch $B_{\mathrm{Mg}}$ reached the lowest value with $2 \cdot 2 \cdot 10^{3} \mathrm{mg} /\left(\mathrm{cm}^{2} \mathrm{a}\right)$. Based on these results and the pore distributions of the CT scans, batches $A_{M g}$ and $B_{M g}$ are used for subsequent fatigue and corrosion fatigue tests. The different corrosion properties and pore distributions suggest the greatest differences in fatigue behavior.

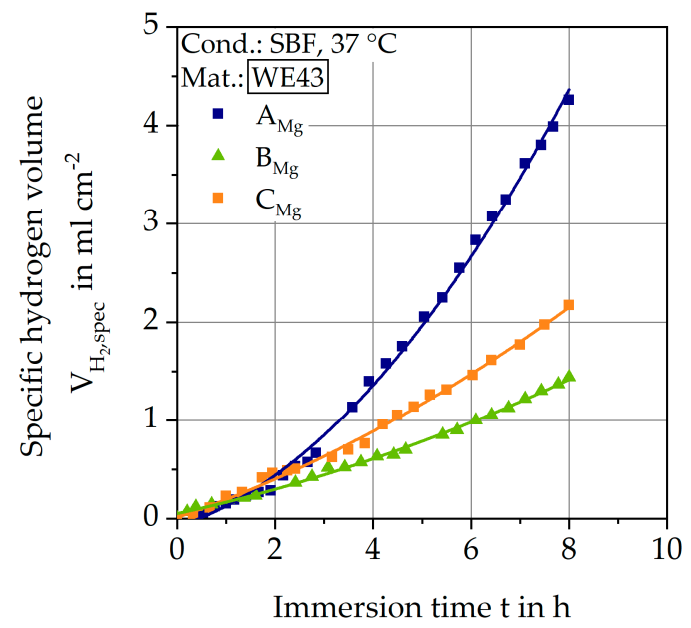

Figure 17. Results of immersion tests in $\mathrm{SBF}$ at $37^{\circ} \mathrm{C}$.

Table 4. Characteristic values of the potentiodynamic polarization and immersion tests.

\begin{tabular}{cccc}
\hline & & \multicolumn{2}{c}{$\dot{\mathbf{m}}_{\text {corr }}$ in $\mathbf{~ m ~ c m ~}^{-2} \mathbf{a}^{-\mathbf{1}}$} \\
\hline Batch & $\mathbf{E}_{\text {corr }}$ in V & PDP & Immersion \\
\hline $\mathrm{A}_{\mathrm{Mg}}$ & -1.50 & $1.5 \cdot 10^{3}$ & $7.2 \cdot 10^{3}$ \\
\hline $\mathrm{B}_{\mathrm{Mg}}$ & -1.51 & $0.6 \cdot 10^{3}$ & $2.2 \cdot 10^{3}$ \\
\hline $\mathrm{C}_{\mathrm{Mg}}$ & -1.56 & $1.1 \cdot 10^{3}$ & $3.1 \cdot 10^{3}$ \\
\hline
\end{tabular}

\subsection{Corrosion Fatigue Tests}

Figure 18 shows the results of the CAT in form of the material reaction with the maximum displacement $\Delta s_{\max }$ as a function of the number of cycles $\mathrm{N}$ in a semi-logarithmic plot, hence, the course within the first 100 cycles can be seen especially.

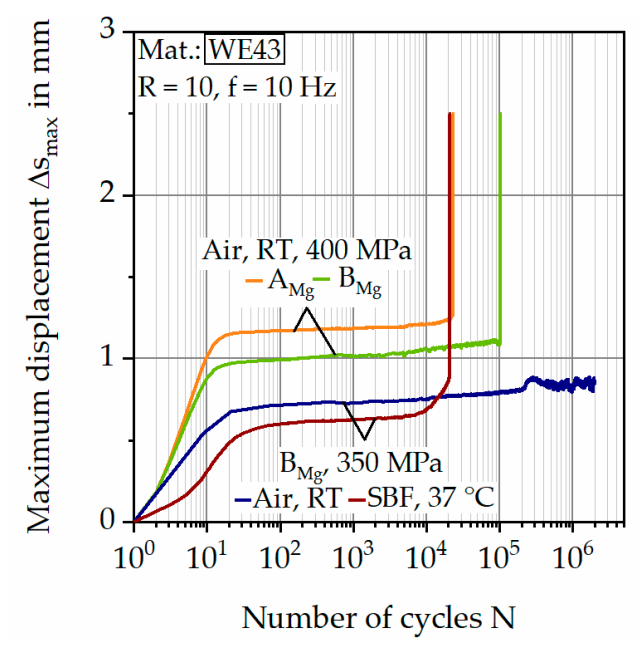

Figure 18. $\Delta \mathrm{s}_{\max }-\mathrm{N}$ curves for different batches and testing conditions. 
Two parameter sets (batches and environmental conditions) were compared with otherwise constant parameters. A similar behavior within the first 40 cycles is recognizable for the four displayed curves, the respective curve is progressive and approaches a saturation value, followed by a plateau, in which the change of $\Delta s_{\max }$ is moderate. Both experiments in air (at $400 \mathrm{MPa}$ ) also show a similar course before failure occurs. The failure is announced only slightly by an increase of $\Delta \mathrm{s}_{\max }$, consequently, the samples fail brittle. The initial deformation is greater for batch $\mathrm{A}_{\mathrm{Mg}}$ and the failure occurs earlier. For the shown test in the SBF, a progressive path before failure is observed.

The summarized results of the CAT of both batches in SBF at $37^{\circ} \mathrm{C}$ and in air at RT are shown as trend S-N curves in Figure 19. For the tests in air, differences in the low cycle fatigue (LCF) range between the two batches are visible, for a technical maximum compression stress $\sigma_{\max }=450 \mathrm{MPa}$ batch $A_{M g}$ achieves a number of cycles at failure $N_{f}=10$ cycles, whereas batch $B_{M g}$ achieves $N_{f}=35,979$ cycles. In the high cycle fatigue (HCF) range, a similar trend can be seen for $\sigma_{\max }=400 \mathrm{MPa}$, nevertheless, the run outs $\left(\mathrm{N}_{\text {limit }}=2 \cdot 10^{6}\right.$ cycles) for $\sigma_{\max }=350 \mathrm{MPa}$ (batch $\mathrm{B}_{\mathrm{Mg}}$ ) and $375 \mathrm{MPa}$ (batch $\mathrm{A}_{\mathrm{Mg}}$ ) are achieved in a similar range of $\sigma_{\max }$. For both batches, the respective data points of the CAT in air can be approximated linearly.

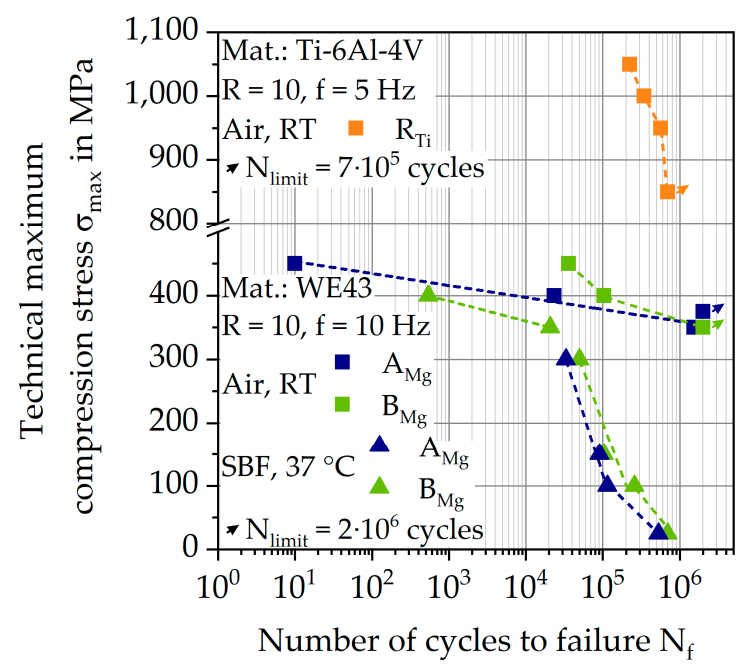

Figure 19. Trend $S-N$ curves for batches $A_{M g}$ and $B_{M g}$ of magnesium and batch $R_{T i}$ of titanium at $R T$ and in SBF at $37^{\circ} \mathrm{C}$.

With regard to Ti-6Al-4V, a higher overall maximum compression stress $\sigma_{\max }$ can be achieved (Figure 19). Under a load of $\sigma_{\max }=1050 \mathrm{MPa}$, a total number of cycles to failure $\mathrm{N}_{\mathrm{f}}=224,542$ cycles was determined, which subsequently increases to $\mathrm{N}_{\mathrm{f}}=564,550$ cycles under $\sigma_{\max }=950 \mathrm{MPa}$, implicating the high strength of titanium in comparison to the magnesium alloy. A general approach for testing the corrosion fatigue properties of Ti-6Al-4V is to immerse specimens for a certain time, which can be up to several weeks in SBF [6,7], and subsequently test them. As can be seen in the investigations from Liu et al. [7], this can have little to no influence on the fatigue properties of Ti-6Al-4V in the HCF range. For enabling the same testing conditions for both materials, no fatigue tests under SBF were carried out for Ti- $6 \mathrm{Al}-4 \mathrm{~V}$, since it can be assumed that the influence of corrosion on the fatigue properties of Ti-6Al-4V is negligible for short time experiments.

However, the results of magnesium alloy in SBF show different material behavior. In the LCF range of the CAT in SBF, batch $B_{\mathrm{Mg}}$ reaches $\mathrm{N}_{\mathrm{f}}=542$ cycles at $\sigma_{\max }=400 \mathrm{MPa}$, and 20,670 cycles at $\sigma_{\max }=350 \mathrm{MPa}$. The trend S-N curve then bends, and $\mathrm{N}_{\mathrm{f}}$ for both batches increases only slightly for decreasing $\sigma_{\max }$. Compared to $\sigma_{\max }=300 \mathrm{MPa}$ with $\mathrm{N}_{\mathrm{f}}=33,229$ cycles for batch $\mathrm{A}_{\mathrm{Mg}}$ and 49,503 cycles for batch $B_{\mathrm{Mg}}$, the number of cycles at failure for $\sigma_{\max }=50 \mathrm{MPa}$ only increases to $\mathrm{N}_{\mathrm{f}}=236,966$ and 388,045 cycles, respectively. For the lowest technical maximum compression stress of $\sigma_{\max }=25 \mathrm{MPa}$, the number of cycles to failure for batch $\mathrm{B}_{\mathrm{Mg}}$ is $\mathrm{N}_{\mathrm{f}}=691,729$ cycles. A run out could not be achieved 
for both batches, but the course in the HCF range seems to flatten out towards a higher number of cycles. For each $\sigma_{\max }$ of the CAT in SBF, batch $B_{M g}$ achieves a higher $\mathrm{N}_{\mathrm{f}}$ than batch $\mathrm{A}_{\mathrm{Mg}}$. Lower values for $\sigma_{\max }$ could not be accomplished regarding the calibration of the machine used.

\subsection{Fractography}

Results from the fractographic analysis are presented in Figure 20, whereas Figure 20a shows the fractured surface of batch $\mathrm{A}_{\mathrm{Mg}}\left(\sigma_{\max }=400 \mathrm{MPa}, \mathrm{N}_{\mathrm{f}}=23,192\right.$ cycles $)$ and Figure 20b shows the corresponding surface of batch $\mathrm{B}_{\mathrm{Mg}}\left(\sigma_{\max }=400 \mathrm{MPa}, \mathrm{N}_{\mathrm{f}}=102,848\right.$ cycles $)$. Both specimens were tested in air at RT. It can be seen that the specimens failed under an angle of $45^{\circ}$ and fracture surfaces slipped off each other during failure, implicating a high degree of deformation. It can be noticed that crack initiation takes place at the surface, due to the presence of high surface roughness. However, primary crack initiation cannot be easily identified. This might be attributed to the increased surface roughness and the presence of notch-like defects at the surface of additively manufactured parts.

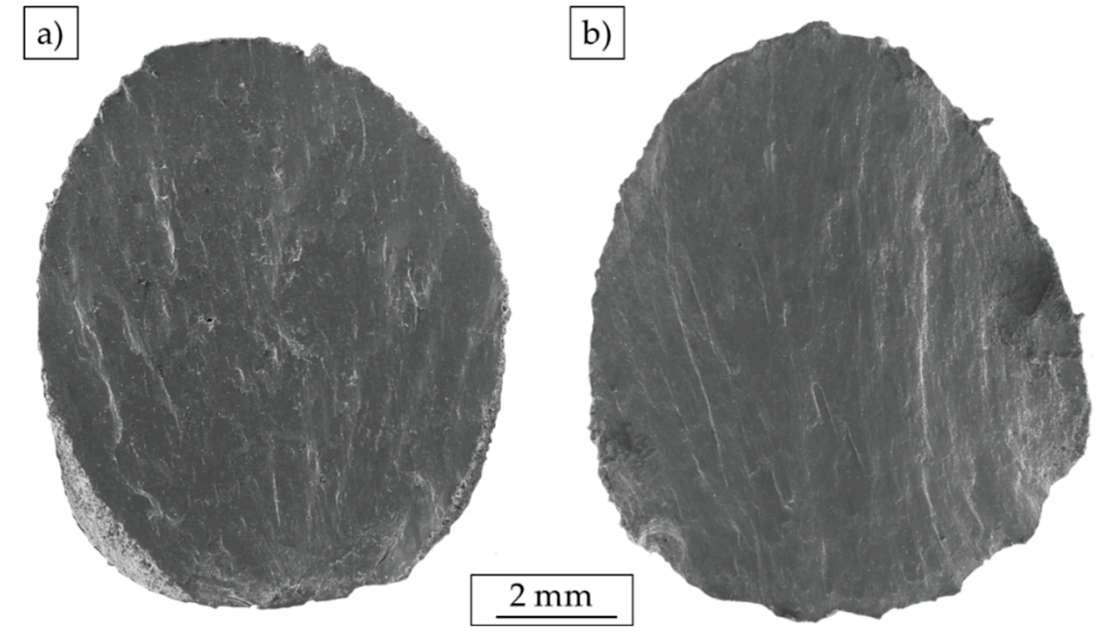

Figure 20. SEM images of fractured specimens tested at $400 \mathrm{MPa}$ in air at RT: (a) batch $\mathrm{A}_{\mathrm{Mg}}\left(\mathrm{N}_{\mathrm{f}}=23,192\right.$ cycles) and (b) batch $\mathrm{B}_{\mathrm{Mg}}\left(\mathrm{N}_{\mathrm{f}}=102,848\right.$ cycles $)$.

An exemplary fractured surface of a specimen, tested in SBF at $37^{\circ} \mathrm{C}$, with a corresponding magnification of crack initiation, is depicted in Figure 21. As can be seen, failure occurred as well under an angle of $45^{\circ}$. However, corrosion pits can be found at the near-surface of the specimen, which locally support crack initiation. Nevertheless, even here, no single crack initiation can be detected.

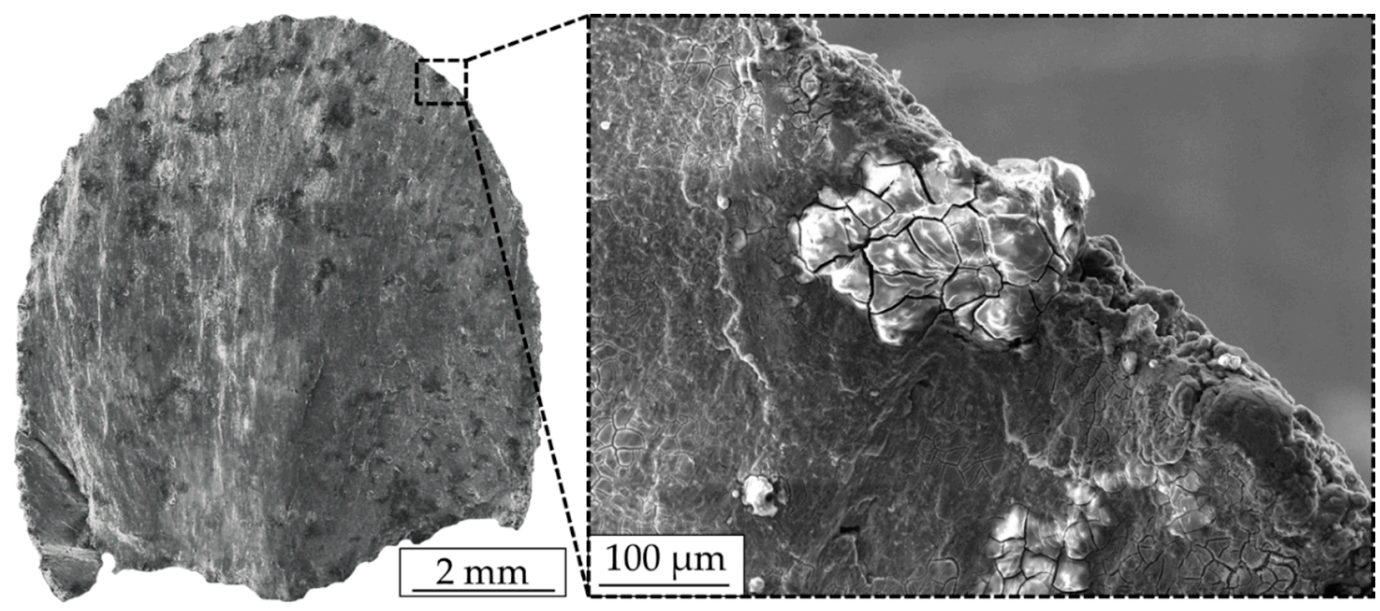

Figure 21. SEM images of an exemplary fractured surface of batch $\mathrm{B}_{\mathrm{Mg}}$, tested in SBF at $37^{\circ} \mathrm{C}$. 


\section{Discussion}

\subsection{Computer Tomography}

The CT analysis is facing the problem of high image noise. It partially could not be differentiated between very small real pores and dark pixels that were to lead back to the noise. Therefore, more pores, especially very small ones, were detected than actually exist in the specimens. This results in a decreased relative density and also a smaller mean pore size. On the other hand, pores appear smaller than they actually are on CT images. Accordingly, the real maximum pore size is bigger than the one evaluated in the CT analysis. The described problem could be solved partially by excluding the smallest detected pores from the calculation, as they were likely to be image artifacts. The differences and high variations in calculated relative density could also be shown by the comparison with conventionally achieved values for the relative density, which all were lower than the CT values for titanium and similar or higher for magnesium. The alternating values referred to the different methods to identify the relative densities, which can be attributed to measurements variations. The relative densities determined by image analysis have similar dependencies and are in the same range as those calculated from CT data. For a more precise evaluation of the relative density, a higher CT resolution and a reduction of image noise would be necessary. Besides the image quality, the positioning of the parts and the slightly varying scale of the resulting images also influences the analysis accuracy that should be kept in mind. It is therefore important to place all samples of an experimental run precisely in the same way inside the CT device.

The different pore geometries observed are caused by different defect mechanisms. The small spherical pores are caused by trapped gas, often due to high energy input, whereas big and irregular pores indicate insufficient melting and a lack of fusion as a result of too low energy input or poor wettability.

The high standard deviation, especially for batch $\mathrm{A}_{\mathrm{Mg}}$ and $\mathrm{A}_{\mathrm{Ti}}$, means that in these specimens there are slices or layers with very big pores or a high number of pores, and on the other hand, slices or layers with a higher density. It could also be shown that the standard deviation is linked to the overall relative density of the specimen and increases with decreasing relative density. High standard deviation in part properties and as a result a lack of reproducibility are known challenges in additive manufacturing, and should therefore be taken into account when it comes to the planning and conduction of experiments.

\subsection{Microstructure}

\subsubsection{Magnesium}

The fine-grained microstructure of the alloy is expected due to the fast cooling of the melting pools in additive manufacturing [40]. In addition, for L-BPF-processed magnesium alloys, it has been reported that it possibly undergoes grain boundary locking via Zener pinning mechanisms associated to Y-rich phases in the intergranular region [41,42]. This tends to reduce the grain growth associated to local recrystallization in the partially molten regions of the heat affected zone, thus maintaining the fine cellular-dendritic grains along the alloy microstructure, as verified in this study.

This grain refinement is expected to generally increase the mechanical properties like ultimate tensile and yield strength of the components through the Hall-Petch effect of inhibiting the motion of dislocations $[43,44]$. Nevertheless, Qin et al. argue that this is not expected to be a major effect for magnesium alloys [45]. Moreover, fine-grained microstructures are described as bringing higher corrosion resistance to magnesium systems, since the finer grains would be prone to produce more uniform corrosion products, a denser passivation layer and, ultimately, slow and homogeneous corrosion $[44,46,47]$. 


\subsubsection{Titanium}

Titanium and corresponding alloys have a relatively poor thermal conductivity. The alloy Ti-6Al-4V processed in this work has a thermal conductivity of $7 \mathrm{~W} /(\mathrm{m} \mathrm{K})$ at room temperature [48], leading to an accumulation of heat in the built part. Due to this, the already solidified material is remelted several times and the heat affected zone extends over several previous layers. As a result, the grains consisting of the high temperature $\beta$-phase grow across the layers and no single melt pools or layer boundaries are visible. The $\beta$-grains grow in the opposite direction of the heat flow. For the largest part of the volume, this means that the grains grow in the building direction. Near the lateral surfaces, the grain growth is less oriented due to the different and more complex heat flow in the cross region between the dense material and unmelted powder.

The width of the $\beta$-grains depends on the chosen parameter values, and therefore the laser energy input. Higher speeds lead to increased cooling rates so that there is less time for the grains to grow. As a result, a finer grain structure is received. On the other hand, a higher energy input provides more thermal energy for the grain growths, leading to a coarser microstructure.

In L-PBF, high cooling rates of 104-106 K/s are achieved [49,50], preventing the formation of the equilibrium $\alpha+\beta$ microstructure. Instead, the $\beta$-phase is diffusionless, transformed into $\alpha^{\prime}$-martensite that fills the prior- $\beta$ grains. Thereby, the amount of the martensite phase depends on the cooling rate, which has to be sufficiently high, and the build temperature, which needs to be below the martensite start temperature [30]. As described by [38], a hierarchical structure of different types of martensite (primary, secondary, tertiary, quartic) was observed. This morphology can be led back to the cyclic reheating and remelting that is typical for the L-PBF process and can be influenced by varying the processing parameters [30].

Similar to magnesium, the microstructure, and therefore the grain size as well as the element distribution, influence the corrosion resistance and fatigue crack resistance, as stated by different literature [51-53].

\subsection{Corrosion Behavior}

In general, the results of the two methods (PDP and immersion test) for determining the corrosion rate $\dot{\mathrm{m}}_{\text {corr }}$ of the three batches show quantitatively different results (Table 4). For all three batches, $\dot{\mathrm{m}}_{\text {corr }}$ determined by the immersion tests are higher. However, this coincides with literature data, since, apart from the problem of the NDE, the origin of which is still being discussed [17], this leads to lower corrosion current densities $i_{\text {corr }}$, measured with comparable methods. In addition to the test parameters (potential range, potential feed, etc.), the evaluation method of $i_{\text {corr }}$ in the Tafel plot also influences the calculated $\dot{m}_{\text {corr }}$, leading to high standard deviations within this method [54]. Other studies exhibited values of $\mathrm{i}_{\text {corr }}$ in a wide range between 11.9 and $409 \mu \mathrm{A} / \mathrm{cm}^{2}[33,55,56]$ for different treatment methods of the WE43 alloy so that the results of this study $\left(160.6 \leq \mathrm{i}_{\text {corr }} \leq 380.3 \mu \mathrm{A} / \mathrm{cm}^{2}\right)$ are within this range. The magnesium alloy WE43 is nominally a wrought material, but it is difficult to compare the corrosion properties because different treatment processes, especially heat treatments and other electrolytes, are used for these alloys [57]. Chu and Marquis determined lower values of $\mathrm{i}_{\text {corr }}=70$ and $85 \mu \mathrm{A} / \mathrm{cm}^{2}$, respectively, in PDP measurements, however, in contrast to the present study, a $3.5 \% \mathrm{NaCl}$ solution was used [58]. Furthermore, for both test methods, the surfaces are polished at the beginning of the test. Due to the longer duration of the immersion tests, this is not continuously given within the test, so that an increased corroded surface area, and thus also an increased hydrogen formation, occurs. Nevertheless, the results prove that a qualitative evaluation of $\dot{\mathrm{m}}_{\text {corr }}$ based on PDP is possible and thus a statement about different material states can be made in a time-saving manner. A comparison with in vivo corrosion rates is difficult. On one hand, there are generally less in vivo results, on the other hand, Martinez Sanchez et al. showed in a review article that the corrosion rates in vitro exceed the results in vivo, and within one material, strong variations occur due to different in vitro testing conditions. For the alloy WE43, the average in vitro corrosion rate is 1.6 times higher 
than the in vivo value, with immersion tests executed with a SBF, Earle's balanced salt solution, and minimum essential medium showing the best correlations to in vivo tests [59].

\subsection{Fatigue Behavior}

For the two batches tested in fatigue and corrosion fatigue tests, there are clear differences, especially in the LCF range in air at RT. In the HCF range batch $B_{\mathrm{Mg}}$ achieves a run out at $\sigma_{\max }=350 \mathrm{MPa}$, whereas batch $\mathrm{A}_{\mathrm{Mg}}$ has a number of cycles to failure $\mathrm{N}_{\mathrm{f}}=1.52 \cdot 10^{6}$ cycles. These differences are mainly due to the different pore areas, as can be seen in Figure 8.

Due to the additional superposition through the SBF, the fatigue life of both batches decreases drastically. The bend in the trend S-N curve in the range $350 \mathrm{MPa} \leq \sigma_{\max }<250 \mathrm{MPa}$ for batch $\mathrm{B}_{\mathrm{Mg}}$ can probably be explained by the increased exposure time to the electrolyte and the resulting corrosion. The strongly decreasing slope for $\sigma_{\max } \leq 250 \mathrm{MPa}$ can thus also be justified by the increasing exposure time. Nevertheless, it should be noted that due to corrosion, the cross-section of the specimens decreases sharply with increasing test duration and thus the true stress increases. An example of this is the cross-section of one sample from batch $\mathrm{B}_{\mathrm{Mg}}\left(\sigma_{\max }=25 \mathrm{MPa}, \mathrm{N}_{\mathrm{f}}=691,729\right.$ cycles $)$. After the test, the cross-section was reduced to $\mathrm{A} \approx 28 \mathrm{~mm}^{2}$ (from $\mathrm{A}_{0}=40.9 \mathrm{~mm}^{2}$ ), so that based on the initial force a true stress of $\sigma_{\text {max,true }} \approx 36.4 \mathrm{MPa}$ was reached at the end of the test. Both batches show very similar trend S-N curves for the tests in SBF, the course is in a good approximation parallel and they achieve a similar number of cycles to failure for the same stress levels. Based on porosity and corrosion rates, batch $\mathrm{B}_{\mathrm{Mg}}$ also seems to have superior properties for corrosion fatigue, however, the general corrosive influence seems to predominate. Another possible explanation for the drastic decrease in fatigue strength might be notch-like defects at the surface, which result from plate-pile stacking defects and partially melted powder particles sticking on the specimen surface [60]. This can lead to stress corrosion, which was also observed by Bian et al. [25]. As can be seen in the results from the fractographic analysis, multiple crack initiation sites are present, resulting in the formation of several corrosion pits at the same time. With regard to available literature, a comparison with other data is difficult, due to various reasons. On one hand, there are generally few studies on the corrosion fatigue behavior of magnesium alloys in body-like fluids; on the other hand, both other magnesium alloys and test conditions were used in the existing studies. Studies on the corrosion fatigue behavior of additively manufactured magnesium alloys are not known to the authors. Zhao et al. investigated the influence of a precorrosion with different immersion times on the fatigue behavior [61]. Although this showed an influence of the precorrosion, a superimposed corrosive mechanical load nevertheless leads to far different damage mechanisms. Recent studies on corrosion fatigue behavior used a stress ratio of $R=-1$ which deviates from these tests, and also a test frequency of $f=10 \mathrm{~Hz}[24,25,62]$. The common result of these studies was a strong decrease of the fatigue properties in body-like fluids compared to the reference in air, as well as a change of the failure mechanism. In air, crack initiation was caused by structural or mechanical defects, whereas in the electrolyte, initiation was caused by corrosion pits and thus drastically reduced the service life. Jafari et al. investigated the fatigue behavior of $\mathrm{Mg}-1 \mathrm{Zn}-0.3 \mathrm{Ca}$ for two extrusion temperatures. For both material states, the fatigue strength in air $\left(\mathrm{N}_{\text {limit }}=10^{7}\right.$ cycles $)$ decreased from 106 and $81 \mathrm{MPa}$, respectively, to approximately $78 \mathrm{MPa}$ for $\mathrm{N}_{\text {limit }}=5 \cdot 10^{5}$ cycles. Despite similar properties in the PDP measurements, a stronger decrease of the corrosion fatigue properties in comparison to the reference condition in air was observed for the lower extrusion temperature [24]. For the calcium-containing alloys, $\mathrm{Mg}-2 \mathrm{Zn}-0.2 \mathrm{Ca}$ and $\mathrm{Mg}-1 \mathrm{Ca}$, similar ratios between fatigue strength and corrosion fatigue strength could be determined for $\mathrm{N}_{\text {limit }}=4 \cdot 10^{6}$ cycles. Thus, the values decreased from approximately $90 \mathrm{MPa}$ to 70 and $68 \mathrm{MPa}$, respectively. A further finding of this study was the increase of $\dot{\mathrm{m}}_{\text {corr }}$ due to dynamic flow conditions in comparison to static fluids [25], which could also be proven by Levesque et al. [63]. Gu et al. also investigated the magnesium alloy WE43 and were able to determine a corrosion fatigue strength of $40 \mathrm{MPa}$ for $\mathrm{N}_{\text {limit }}=10^{7}$ cycles, as well as a stress ratio of $\mathrm{R}=-1$ through tests in a SBF [52]. Jafari et al. refer the determined corrosion fatigue strength to a number of cycles; $\mathrm{N}=10^{5}$ cycles, which, according to Taylor et al. is the fatigue limit for human bone 
at 23-30 MPa [63]. Such a number of cycles are achieved for magnesium alloy WE43 at $\sigma_{\max }=150 \mathrm{MPa}$ (batch $\mathrm{B}_{\mathrm{Mg}}$ ) or $100 \mathrm{MPa}$ (batch $\mathrm{A}_{\mathrm{Mg}}$ ), so that there is sufficient fatigue strength in relation to Taylor et al. A limitation of this investigation is the deviation from the orthopedically maximum load frequency of $3 \mathrm{~Hz}$ [14], and the influence of a higher frequency has to be clarified. Furthermore, the used frequency $\mathrm{f}_{\mathrm{Mg}}=10 \mathrm{~Hz}$ reduces the test time and, consequently, also the exposure time to the electrolyte.

\section{Conclusions and Outlook}

Within the scope of this study, corrosion and corrosion fatigue tests were performed on the magnesium alloy WE43, and for reference purposes, on the titanium alloy Ti-6Al-4V to characterize the influence of the manufacturing parameters used in the laser powder bed fusion (L-PBF) process. Based on these results, the following conclusions can be drawn:

For magnesium, in particular, a strong dependence on the pore distribution and size as well as the microstructure was discernible for the selected manufacturing parameters. These properties hardly differed for titanium, due to chosen parameter combinations with very similar energy densities, consequently, only one parameter set was used for titanium for further investigations.

The corrosion rates, determined by the potentiodynamic polarization and immersion tests, also showed a dependence on the manufacturing parameters, which was attributed to the different microstructures. The corrosion rates determined by potentiodynamic polarization were below the values from the immersion tests. Furthermore, strong variations within one parameter set were measured. Nevertheless, a time-efficient estimation of the corrosion rates of different material states on the basis of potentiodynamic polarization is possible.

Based on the porosity, microstructure, and corrosion behavior, differences in fatigue and corrosion fatigue behavior could also be determined. For the reference tests in air, major differences were found between the two magnesium batches tested in the low cycle fatigue range. For the corrosion fatigue tests in SBF, there were continuous differences which, however, have to be evaluated as low, so that the general corrosion influence on the mechanical properties seems to be dominant here. Especially for increasing test durations, the mechanical fatigue properties decrease drastically, so that the trend S-N curve is bent. Based on the high surface roughness, primary crack initiation is difficult to determine, since multiple crack initiation is present, which locally supports corrosion. The reference alloy Ti-6Al-4V shows a higher overall strength in the fatigue tests.

Based on these findings, further studies should determine the exact influences of the individual manufacturing parameters in the L-PBF process on the macro- and microstructure, and thus on the corrosion and corrosion fatigue properties. Furthermore, the variations in the determination of corrosion rates must be minimized by a standardized procedure. An adaptation of the test load and thus of the test stress in the single-stage tests on the basis of the decreasing cross-section, so that tests are carried out at a constant true stress, is useful for understanding the influence of the macrostructure and microstructure on the fatigue properties.

Author Contributions: Specimen manufacturing, microstructural, and computer tomographical investigations were carried out by Y.W. and N.E.; corrosion, fatigue, and corrosion fatigue tests on magnesium were performed by N.W.; the fatigue tests on titanium were performed by D.K.; fractographic analysis was performed by D.K. and N.W.; the original draft was written by N.W., D.K., Y.W., and N.E.; F.W., L.O., J.H., J.T., and C.H. supervised the project and reviewed the manuscript.

Funding: The authors thank the German Research Foundation (Deutsche Forschungsgemeinschaft, DFG) for its financial support within the research projects "Development and validation of an in vitro short-time testing method for the prediction of the in vivo behavior of absorbable metallic implant materials" (SM 214/4-1, WA 1672/40-1) and "Damage tolerance evaluation of electron beam melted cellular structures by advanced characterization techniques" (NI 1327/13-1, WA 1672/32-1).

Acknowledgments: Authors acknowledge financial support by German Research Foundation and TU Dortmund University (Technische Universität Dortmund) within the funding programme Open Access Publishing.

Conflicts of Interest: The authors declare no conflict of interest. 


\section{References}

1. Arsiwala, A.; Desai, P.; Patravale, V. Recent advances in micro/nanoscale biomedical implants. J. Control Release 2014, 189, 25-45. [CrossRef] [PubMed]

2. Wilson, J. Metallic Biomaterials. In Fundamental Biomaterials; Elsevier Duxford: Cambridge, MA, USA, 2018; pp. 1-33.

3. Murr, L.E.; Gaytan, S.M.; Medina, F.; Martinez, E.; Martinez, J.L.; Hernandez, D.H.; Machado, B.I.; Ramirez, D.A.; Wicker, R.B. Characterization of Ti-6Al-4V open cellular foams fabricated by additive manufacturing using electron beam melting. Mater. Sci. Eng. A 2010, 527, 1861-1868. [CrossRef]

4. Dallago, M.; Fontanari, V.; Torresani, E.; Leoni, M.; Pederzolli, C.; Potrich, C.; Benedetti, M. Fatigue and biological properties of Ti-6Al-4V ELI cellular structures with variously arranged cubic cells made by selective laser melting. J. Mech. Behav. Biomed. Mater. 2018, 78, 381-394. [CrossRef] [PubMed]

5. Singh, R.; Lee, P.D.; Dashwood, R.J.; Lindley, T.C. Titanium foams for biomedical applications: A review. Mater. Technol. 2010, 25, 127-136. [CrossRef]

6. Doi, K.; Miyabe, S.; Tsuchiya, H.; Fujimoto, S. Degradation of Ti-6Al-4V alloy under cyclic loading in a simulated body environment with cell culturing. J. Mech. Behav. Biomed. Mater. 2016, 56, 6-13. [CrossRef] [PubMed]

7. Liu, Y.J.; Ouyang, Q.L.; Tian, R.H.; Wang, Q.Y. Fatigue Properties of Ti-6Al-4V Subjected to Simulated Body Fluid. Struct. Longev. 2009, 2, 169-176.

8. Orlov, D.; Joshi, V.; Solanki, K.N.; Neelameggham, N.R. Magnesium Technology; Springer International Publishing: Cham, Germany, 2018.

9. Saris, N.-E.L.; Mervaala, E.; Karppanen, H.; Khawaja, J.A.; Lewenstam, A. Magnesium-An update on physiological, clinical and analytical aspects. Clin. Chim. Acta 2000, 294, 1-26. [CrossRef]

10. Staiger, M.P.; Pietak, A.M.; Huadmai, J.; Dias, G. Magnesium and its alloys as orthopedic biomaterials: A review. Biomaterials 2006, 27, 1728-1734. [CrossRef] [PubMed]

11. Jung, O.; Smeets, R.; Porchetta, D.; Kopp, A.; Ptock, C.; Müller, U.; Heiland, M.; Schwade, M.; Behr, B.; Kröger, N. Optimized in vitro procedure for assessing the cytocompatibility of magnesium-based biomaterials. Acta Biomater. 2015, 23, 354-363. [CrossRef]

12. Jung, O.; Smeets, R.; Kopp, A.; Porchetta, D.; Hiester, P.; Heiland, M.; Friedrich, R.E.; Precht, C.; Hanken, H.; Gröbe, A.; et al. PEO-generated Surfaces Support Attachment and Growth of Cells In Vitro with No Additional Benefit for Micro-roughness in Sa (0.2-4 $\mu \mathrm{m})$. In Vivo 2016, 30, 27-33.

13. Li, Z.; Gu, X.; Lou, S.; Zheng, Y. The development of binary Mg-Ca alloys for use as biodegradable materials within bone. Biomaterials 2008, 29, 1329-1344. [CrossRef] [PubMed]

14. Singh Raman, R.K.; Jafari, S.; Harandi, S.E. Corrosion fatigue fracture of magnesium alloys in bioimplant applications: A review. Eng. Fract. Mech. 2015, 137, 97-108. [CrossRef]

15. Kannan, M.B.; Raman, R.K.S. In vitro degradation and mechanical integrity of calcium-containing magnesium alloys in modified-simulated body fluid. Biomaterials 2008, 29, 2306-2314. [CrossRef] [PubMed]

16. Zander, D.; Schnatterer, C. The influence of manufacturing processes on the microstructure and corrosion of the AZ91D magnesium alloy evaluated using a computational image analysis. Corros. Sci. 2015, 98, $291-303$. [CrossRef]

17. Frankel, G.S.; Fajardo, S.; Lynch, B.M. Introductory lecture on corrosion chemistry: A focus on anodic hydrogen evolution on $\mathrm{Al}$ and Mg. Faraday Discuss. 2015, 180, 11-33. [CrossRef] [PubMed]

18. Höche, D.; Blawert, C.; Lamaka, S.V.; Scharnagl, N.; Mendis, C.; Zheludkevich, M.L. The effect of iron re-deposition on the corrosion of impurity-containing magnesium. Phys. Chem Chem Phys. 2016, 18, 1279-1291. [CrossRef]

19. Birbilis, N.; King, A.D.; Thomas, S.; Frankel, G.S.; Scully, J.R. Evidence for enhanced catalytic activity of magnesium arising from anodic dissolution. Electrochim. Acta 2014, 132, 277-283. [CrossRef]

20. Chen, C.; Liu, T.; Lv, C.; Lu, L.; Luo, D. Study on cyclic deformation behavior of extruded Mg-3Al-1Zn alloy. Mater. Sci. Eng. A 2012, 539, 223-229. [CrossRef]

21. Feng, C.Y.; Wang, X.G.; Tang, P.H. Research on Low Cycle Fatigue Behavior and Life Prediction of Magnesium Alloy AZ91D. Adv. Mater. Res. 2012, 482, 575-580. [CrossRef]

22. Patel, H.A.; Rashidi, N.; Chen, D.L.; Bhole, S.D.; Luo, A.A. Cyclic deformation behavior of a super-vacuum die cast magnesium alloy. Mater. Sci. Eng. A 2012, 546, 72-81. [CrossRef] 
23. Jafari, S.; Singh Raman, R.K.; Davies, C.H.J. Corrosion fatigue of a magnesium alloy in modified simulated body fluid. Eng. Fract. Mech. 2015, 137, 2-11. [CrossRef]

24. Jafari, S.; Raman, R.K.S.; Davies, C.H.J.; Hofstetter, J.; Uggowitzer, P.J.; Löffler, J.F. Stress corrosion cracking and corrosion fatigue characterisation of $\mathrm{MgZn1Ca0.3} \mathrm{(ZX10)} \mathrm{in} \mathrm{a} \mathrm{simulated} \mathrm{physiological} \mathrm{environment.}$ J. Mech. Behav. Biomed. Mater. 2017, 65, 634-643. [CrossRef] [PubMed]

25. Bian, D.; Zhou, W.; Liu, Y.; Li, N.; Zheng, Y.; Sun, Z. Fatigue behaviors of HP-Mg, Mg-Ca and Mg-Zn-Ca biodegradable metals in air and simulated body fluid. Acta Biomater 2016, 41, 351-360. [CrossRef] [PubMed]

26. Krujatz, F.; Lode, A.; Seidel, J.; Bley, T.; Gelinsky, M.; Steingroewer, J. Additive Biotech-Chances, challenges, and recent applications of additive manufacturing technologies in biotechnology. New Biotechnol. 2017, 39, 222-231. [CrossRef] [PubMed]

27. Singh, S.; Ramakrishna, S. Biomedical applications of additive manufacturing: Present and future. Curr. Opin. Biomed. Eng. 2017, 2, 105-115. [CrossRef]

28. Tan, X.P.; Tan, Y.J.; Chow, C.S.L.; Tor, S.B.; Yeong, W.Y. Metallic powder-bed based 3D printing of cellular scaffolds for orthopaedic implants: A state-of-the-art review on manufacturing, topological design, mechanical properties and biocompatibility. Mater. Sci. Eng. C Mater. Biol. Appl. 2017, 76, 1328-1343. [CrossRef] [PubMed]

29. Emmelmann, C.; Sander, P.; Kranz, J.; Wycisk, E. Laser Additive Manufacturing and Bionics: Redefining Lightweight Design. Phys. Procedia 2011, 12, 364-368. [CrossRef]

30. Liu, S.; Shin, Y.C. Additive manufacturing of Ti6Al4V alloy: A review. Mater. Des. 2019, 164, 107552. [CrossRef]

31. Wysocki, B.; Maj, P.; Sitek, R.; Buhagiar, J.; Kurzydłowski, K.; Święszkowski, W. Laser and Electron Beam Additive Manufacturing Methods of Fabricating Titanium Bone Implants. Appl. Sci. 2017, 7, 657. [CrossRef]

32. Tammas-Williams, S.; Zhao, H.; Léonard, F.; Derguti, F.; Todd, I.; Prangnell, P.B. XCT analysis of the influence of melt strategies on defect population in Ti-6Al-4V components manufactured by Selective Electron Beam Melting. Mater. Charact. 2015, 102, 47-61. [CrossRef]

33. Liu, D.; Yang, D.; Li, X.; Hu, S. Mechanical properties, corrosion resistance and biocompatibilities of degradable Mg-RE alloys: A review. J. Mater. Res. Technol. 2019, 8, 1538-1549. [CrossRef]

34. DIN 50106-Testing of Metallic Materials-Compression Test at Room Temperature; German Institute for Standardization: Berlin, Germany, 2016.

35. Kokubo, T.; Kushitani, H.; Sakka, S. Solutions able to reproduce in vivo surface-structure changes in bioactive glass-ceramic A-W3. J. Biomed. Mater. Res. 1990, 24, 721-734. [CrossRef]

36. Voges, I.; Jerosch-Herold, M.; Hedderich, J.; Pardun, E.; Hart, C.; Gabbert, D.D.; Hansen, J.H.; Petko, C.; Kramer, H.-H.; Rickers, C. Normal values of aortic dimensions, distensibility, and pulse wave velocity in children and young adults: A cross-sectional study. J. Cardiovasc. Magn. Reson. 2012, 14, 77. [CrossRef] [PubMed]

37. Hao, Y.-L.; Li, S.-J.; Yang, R. Biomedical titanium alloys and their additive manufacturing. Rare Met. 2016, 35, 661-671. [CrossRef]

38. Yang, J.; Yu, H.; Yin, J.; Gao, M.; Wang, Z.; Zeng, X. Formation and control of martensite in Ti-6Al-4V alloy produced by selective laser melting. Mater. Des. 2016, 108, 308-318. [CrossRef]

39. Agius, D.; Kourousis, K.; Wallbrink, C. A Review of the As-Built SLM Ti-6Al-4V Mechanical Properties towards Achieving Fatigue Resistant Designs. Metals 2018, 8, 75. [CrossRef]

40. Bourell, D.; Kruth, J.P.; Leu, M.; Levy, G.; Rosen, D.; Beese, A.M.; Clare, A. Materials for additive manufacturing. Cirp. Ann. 2017, 66, 659-681. [CrossRef]

41. Zumdick, N.A.; Jauer, L.; Kersting, L.C.; Kutz, T.N.; Schleifenbaum, J.H.; Zander, D. Additive manufactured WE43 magnesium: A comparative study of the microstructure and mechanical properties with those of powder extruded and as-cast WE43. Mater. Charact. 2019, 147, 384-397. [CrossRef]

42. Luo, K.; Zhang, L.; Wu, G.; Liu, W.; Ding, W. Effect of Y and Gd content on the microstructure and mechanical properties of Mg-Y-RE alloys. J. Magnes. Alloy. 2019, 7, 345-354. [CrossRef]

43. Jiang, H.S.; Zheng, M.Y.; Qiao, X.G.; Wu, K.; Peng, Q.Y.; Yang, S.H.; Yuan, Y.H.; Luo, J.H. Microstructure and mechanical properties of WE43 magnesium alloy fabricated by direct-chill casting. Mater. Sci. Eng. A 2017, 684, 158-164. [CrossRef] 
44. Qin, Y.; Wen, P.; Guo, H.; Xia, D.; Zheng, Y.; Jauer, L.; Poprawe, R.; Voshage, M.; Schleifenbaum, J.H. Additive manufacturing of biodegradable metals: Current research status and future perspectives. Acta Biomater. 2019. [CrossRef] [PubMed]

45. Xiang, C.; Gupta, N.; Coelho, P.; Cho, K. Effect of microstructure on tensile and compressive behavior of WE43 alloy in as cast and heat treated conditions. Mater. Sci. Eng. A 2018, 710, 74-85. [CrossRef]

46. Soderlind, J.; Cihova, M.; Schäublin, R.; Risbud, S.; Löffler, J.F. Towards refining microstructures of biodegradable magnesium alloy WE43 by spark plasma sintering. Acta Biomater. 2019. [CrossRef] [PubMed]

47. Sing, S.L.; An, J.; Yeong, W.Y.; Wiria, F.E. Laser and electron-beam powder-bed additive manufacturing of metallic implants: A review on processes, materials and designs. J. Orthop. Res. 2016, 34, 369-385. [CrossRef] [PubMed]

48. Parry, L.; Ashcroft, I.A.; Wildman, R.D. Understanding the effect of laser scan strategy on residual stress in selective laser melting through thermo-mechanical simulation. Addit. Manuf. 2016, 12, 1-15. [CrossRef]

49. Gokuldoss, P.K.; Kolla, S.; Eckert, J. Additive Manufacturing Processes: Selective Laser Melting, Electron Beam Melting and Binder Jetting-Selection Guidelines. Materials 2017, 10, 672. [CrossRef]

50. Qiu, C.; Kindi, M.A.; Aladawi, A.S.; Hatmi, I.A. A comprehensive study on microstructure and tensile behaviour of a selectively laser melted stainless steel. Sci. Rep. 2018, 8, 7785. [CrossRef]

51. Lee, E.; Vasudevan, A.; Sadananda, K. Effects of various environments on fatigue crack growth in Laser formed and IM Ti-6Al-4V alloys. Int. J. Fatigue 2005, 27, 1597-1607. [CrossRef]

52. Bache, M.R.; Evans, W.J. The fatigue crack propagation resistance of Ti-6Al-4V under aqueous saline environments. Int. J. Fatigue 2001, 23, 319-323. [CrossRef]

53. Fleck, C.; Eifler, D. Corrosion, fatigue and corrosion fatigue behaviour of metal implant materials, especially titanium alloys. Int. J. Fatigue 2010, 32, 929-935. [CrossRef]

54. Kirkland, N.T.; Birbilis, N.; Staiger, M.P. Assessing the corrosion of biodegradable magnesium implants: A critical review of current methodologies and their limitations. Acta Biomater. 2012, 8, 925-936. [CrossRef] [PubMed]

55. Davenport, A.J.; Padovani, C.; Connolly, B.J.; Stevens, N.P.C.; Beale, T.A.W.; Groso, A.; Stampanoni, M. Synchrotron X-Ray Microtomography Study of the Role of Y in Corrosion of Magnesium Alloy WE43. Electrochem. Solid State Lett. 2007, 10, C5-C8. [CrossRef]

56. Jin, W.; Wu, G.; Feng, H.; Wang, W.; Zhang, X.; Chu, P.K. Improvement of corrosion resistance and biocompatibility of rare-earth WE43 magnesium alloy by neodymium self-ion implantation. Corros. Sci. 2015, 94, 142-155. [CrossRef]

57. Ninlachart, J.; Karmiol, Z.; Chidambaram, D.; Raja, K.S. Effect of heat treatment conditions on the passivation behavior of WE43C Mg-Y-Nd alloy in chloride containing alkaline environments. J. Magnes. Alloys 2017, 5, 147-165. [CrossRef]

58. Chu, P.-W.; Marquis, E.A. Linking the microstructure of a heat-treated WE43 Mg alloy with its corrosion behavior. Corros. Sci. 2015, 101, 94-104. [CrossRef]

59. Martinez Sanchez, A.H.; Luthringer, B.J.C.; Feyerabend, F.; Willumeit, R. Mg and Mg alloys: How comparable are in vitro and in vivo corrosion rates? A review. Acta Biomater. 2015, 13, 16-31. [CrossRef] [PubMed]

60. Körner, C.; Bauereiß, A.; Attar, E. Fundamental consolidation mechanisms during selective beam melting of powders. Model. Simul. Mater. Sci. Eng. 2013, 21, 85011. [CrossRef]

61. Zhao, J.; Gao, L.-L.; Gao, H.; Yuan, X.; Chen, X. Biodegradable behaviour and fatigue life of ZEK100 magnesium alloy in simulated physiological environment. Fatigue Fract. Eng. Mater. Struct. 2015, 38, 904-913. [CrossRef]

62. Gu, X.N.; Zhou, W.R.; Zheng, Y.F.; Cheng, Y.; Wei, S.C.; Zhong, S.P.; Xi, T.F.; Chen, L.J. Corrosion fatigue behaviors of two biomedical Mg alloys-AZ91D and WE43-In simulated body fluid. Acta Biomater. 2010, 6, 4605-4613. [CrossRef]

63. Lévesque, J.; Hermawan, H.; Dubé, D.; Mantovani, D. Design of a pseudo-physiological test bench specific to the development of biodegradable metallic biomaterials. Acta Biomater. 2008, 4, 284-295. [CrossRef]

(C) 2019 by the authors. Licensee MDPI, Basel, Switzerland. This article is an open access article distributed under the terms and conditions of the Creative Commons Attribution (CC BY) license (http://creativecommons.org/licenses/by/4.0/). 